\title{
A Comprehensive Review on Measurement and Correlation Development of Capillary Pressure for Two-Phase Modeling of Proton Exchange Membrane Fuel Cells
}

\author{
Chao Si, ${ }^{1,2}$ Xiao-Dong Wang, ${ }^{1,2}$ Wei-Mon Yan, ${ }^{3}$ and Tian-Hu Wang ${ }^{4}$ \\ ${ }^{1}$ State Key Laboratory of Alternate Electrical Power System with Renewable Energy Sources, North China Electric Power University, \\ Beijing 102206, China \\ ${ }^{2}$ Beijing Key Laboratory of Multiphase Flow and Heat Transfer for Low Grade Energy, North China Electric Power University, \\ Beijing 102206, China \\ ${ }^{3}$ Department of Energy and Refrigerating Air-Conditioning Engineering, National Taipei University of Technology, \\ Taipei 10608, Taiwan \\ ${ }^{4}$ Mathematics and Physics Department, North China Electric Power University, Beijing 102206, China
}

Correspondence should be addressed to Xiao-Dong Wang; wangxd99@gmail.com and Wei-Mon Yan; wmyan@ntut.edu.tw

Received 21 October 2014; Revised 23 March 2015; Accepted 24 March 2015

Academic Editor: Tingyue Gu

Copyright (C) 2015 Chao Si et al. This is an open access article distributed under the Creative Commons Attribution License, which permits unrestricted use, distribution, and reproduction in any medium, provided the original work is properly cited.

\begin{abstract}
Water transport and the corresponding water management strategy in proton exchange membrane (PEM) fuel cells are quite critical for the improvement of the cell performance. Accuracy modeling of water transport in porous electrodes strongly depends on the appropriate constitutive relationship for capillary pressure which is referred to as $p_{c}-s$ correlation, where $p_{c}$ is the capillary pressure and $s$ is the fraction of saturation in the pores. In the present PEM fuel cell two-phase models, the Leverett-Udell $p_{c}-s$ correlation is widely utilized which is proposed based on fitting the experimental data for packed sands. However, the size and structure of pores for the commercial porous electrodes used in PEM fuel cells differ from those for the packed sands significantly. As a result, the Leverett-Udell correlation should be improper to characterize the two-phase transport in the porous electrodes. In the recent decade, many efforts were devoted to measuring the capillary pressure data and developing new $p_{c}-s$ correlations. The objective of this review is to review the most significant developments in recent years concerning the capillary pressure measurements and the developed $p_{c}-s$ correlations. It is expected that this review will be beneficial to develop the improved PEM fuel cell two-phase model.
\end{abstract}

\section{Introduction}

Proton exchange membrane (PEM) fuel cells are one kind of the most promising power generators which can offer clean power source for mobile and stationary applications due to their high efficiency, low start-up temperature, portability, and near-zero emissions [1-4]. The performance of PEM fuel cells is strongly related to the material properties, structure design, and operating conditions. By optimizing the structure design and operating conditions, the reactant transport to the porous electrodes can be significantly enhanced due to the improved water distribution in the cell.
Water management is essential to improve the cell performance [5-11]. The polymer exchange membranes currently used in PEM fuel cells require well hydration to maintain large proton conductivity. Lower membrane water content reduces the cell performance due to the increase of ohmic resistance in the membrane. To avoid membrane dehydration, the reactants usually need to be humidified. On the other hand, the cathode catalyst layer produces water vapor due to electrochemical reactions. The vapor will condense into liquid water when the local partial pressure is higher than the saturation pressure, so that the produced liquid water may accumulate in the pores of the porous electrodes. Moreover, 
the electroosmosis effect also leads to water transport from the anode to the cathode. Thus, if liquid water cannot be removed effectively from the cathode porous electrode, its pores will be blocked, which will significantly increase the mass transfer resistance of the reactants and lead to serious concentration polarization.

In the recent two decades, numerical modeling and simulations have already become powerful tools to predict the cell performance and optimize the cell structure and operation conditions [1,5-7]. Numerical simulations can provide the local transport characteristics and distributions of reactants and water anywhere in the fuel cell; however, this information is very difficult to be observed and measured by experiments. Accurate description of liquid water transport and contribution in the porous electrodes is especially important to improve the accuracy of PEM fuel cell models. Two kinds of PEM fuel cell two-phase models have been developed. One is referred to as the multiphase mixture model and the other is the two-fluid model [1]. The two kinds of models both adopt the so-called volume-average method to treat the porous electrode, so that the real pore structure is not considered. Due to the limitation of the volume-average approach, how to describe the complex twophase interactions in the pores of the porous electrodes is greatly challenging. Since the capillary force and the viscous drag are the main forces governing the liquid water transport in the porous electrodes, Wang et al. $[12,13]$ for the first time introduced a concept of capillary pressure to connect the pressures of reactants and liquid water in the porous electrodes and treated the capillary pressure as a function of the liquid water saturation. The introduction of the correlation of capillary pressure versus liquid water saturation $\left(p_{c}-s\right.$ correlation) greatly simplifies the complexity of two-phase modeling in the porous electrodes and this concept has been extensively adopted by other research groups $[6,7,14-30]$. Up to now, the two kinds of PEM fuel cell two-phase models all use the $p_{c}-s$ correlation and Wang's idea is considered to be the most feasible approach to model the full-scale PEM fuel cell.

Unfortunately, since accurate experimentally determined $p_{c}-s$ correlation for the gas diffusion layer (GDL) was lacking, Wang et al. $[12,13]$ used a Leverett-Udell $p_{c}-s$ correlation, proposed by Leverett [31] and Udell [32] based on the experimental data of packed sands, in their model. The pore size, structure, and wettability of packed sands are greatly different from those of real carbon cloth or carbon paper GDLs; thus, this correlation may be improper to describe the liquid water transport in GDLs of PEM fuel cells [33-35].

In the last decade, many researchers measured the $p_{c}-s$ data for various commercially used GDLs [36-60]. Some studies are also devoted to modifying the Leverett-Udell correlation $[33,37-39]$ or developing a new $p_{c}-s$ correlation $[34,35]$. Up to now, a large number of papers on the $p_{c}-s$ data have been published in open literature and the development is reaching a plateau. A comprehensive review on it is urgently necessary to generate knowledge in this field and make further breakthrough for the fuel cell two-phase modeling.

The aim of this work is to summarize current status and recent advance of capillary pressure measurement and modeling for PEM fuel cells. The review is organized as follows. Section 2 briefly describes the definition of the capillary pressure and the reasons for introduction of $p_{c}-s$ correlation in the PEM fuel cell two-phase modeling. The Leverett-Udell correlation has been extensively used in the PEM fuel twophase models, and hence its disadvantages are also presented in Section 2. Section 3 reviews the measurement methods of the capillary pressure. Section 4 reviews the experimental and simulated data of the capillary pressure for a variety of commercial GDLs. Section 4 also reviews the new $p_{c}-s$ correlations based on fitting the measured experimental data. Section 5 reviews the comparative studies of Leverett-Udell correlation and new $p_{c}-s$ correlation for predicting water transport and distribution in the fuel cell. Finally, the further development directions for the $p_{c}-s$ correlation and PEM fuel cell two-phase modeling are presented in Section 6.

\section{Leverett-Udell Correlation for Capillary Pressure}

For a real porous medium, it is very difficult to model the flow and heat transfer in an individual pore since the pore scale is far less than the scale of the porous medium. Moreover, the pore structure is generally irregular. Therefore, a volume-average method is adopted, which is based on the assumption that there coexist solid matrix and pores for each space point in the porous medium, so that the volumeaveraged parameters such as porosity and permeability can be introduced to characterize the pore structure and porous flow feature. In the current PEM fuel cell two-phase modeling, the volume-average method is also widely adopted to model the porous electrodes [1]. In fact, however, the transport of gaseous reactants and liquid water occurs inside the pores in the real porous electrodes and there exist many interfaces between the two phases. Thus, the mass, momentum, and energy may exchange through the interface, and hence these exchanges in the porous electrodes should be taken into account to construct a reasonable two-phase model.

Unfortunately, in the volume-average method, the concepts, such as porosity, $\varepsilon$, and permeability, $k_{p}$, are introduced to characterize the porous structure. The solid matrix and pores coexist everywhere in the porous media, and the volume fractions for them are $1-\varepsilon$ and $\varepsilon$, respectively. Besides, in the modeling based on the volume-average method, the saturation, $s$, is also introduced to characterize the volume fractions of gaseous phase and liquid phase for each space point, with the fraction of $\varepsilon s$ for the liquid phase and of $\varepsilon(1-s)$ for the gaseous phase. From this point of view, the interfaces between the two phases are neglected.

The above neglect leads to an issue that the exchanges for mass, momentum, and energy through the two-phase interfaces cannot be described. One alternative way to address the issue is to add source terms into the liquid and gas governing equations. For the two-phase modeling in PEM fuel cells, the generation mechanisms for mass source terms in the continuity equation and heat source terms in the energy equation are clear. However, momentum source terms in the momentum equation are very complex; they are not only determined by the phase fractions of the two phases but 
also influenced by the phase distributions of the two phases. For example, when the liquid phase exists in the form of liquid films or discrete drops, the interactions between the two phases are entirely different. It is difficult to accurately measure the phase distribution of the liquid phase in real porous electrodes. Consequently, an accurate description of force source terms in the momentum equation is almost impossible.

Due to the difficulty for accurately modeling the force source terms, Wang et al. [12,13] introduced a concept of capillary pressure which correlated the local pressure difference between the liquid and gaseous phases in the porous electrodes to the local liquid water saturation. The capillary pressure is defined as $[12,13]$

$$
p_{c}=p_{g}-p_{l}
$$

where $p_{c}$ is the capillary pressure, $p_{g}$ is the pressure of the gaseous phase, and $p_{l}$ is the pressure of the liquid phase. Because there were not any experimental data of the capillary pressure versus saturation for porous GDLs, Wang et al. $[12,13]$ introduced a $p_{c}-s$ correlation for packed sands into the modeling of the fuel cell. This correlation can be expressed as [31]

$$
p_{c}=\sigma \cos \theta\left(\frac{\varepsilon}{k_{p}}\right)^{1 / 2} J(s),
$$

where $\sigma$ is the water surface tension and $\theta$ is the contact angle of water on the pore walls. Equation (2) is also referred to as the Leverett correlation, and $J(s)$ is the Leverett $J$-function. It is noted that, by introducing a scaling factor $\sigma \cos \theta\left(\varepsilon / k_{p}\right)^{0.5}$ into the Leverett correlation, the experimental data of $p_{c}-s$ measured in different porous media and with different fluid pairs gather together into a single curve $J(s)$ [54]. Based on Leverett's experimental data, Udell adopted a polynomial fitting to obtain the Leverett $J$-function [32]:

$$
\begin{array}{r}
J(s)=1.417(1-s)-2.120(1-s)^{2}+1.262(1-s)^{3}, \\
\theta<90^{\circ} .
\end{array}
$$

For case with $\theta>90^{\circ}$, Pasaogullari and Wang [61] proposed a modified $J$ function expressed as follows:

$$
J(s)=1.417 s-2.120 s^{2}+1.262 s^{3}, \quad \theta>90^{\circ} .
$$

Equation (2) with $J$ functions expressed by (3a) or (3b) is called the Leverett-Udell correlation in the PEM fuel cell modeling.

Until now, almost all PEM fuel cell two-phase models adopted the Leverett-Udell correlation to characterize the liquid water transport in the porous electrodes. However, this correlation has some obvious drawbacks. The contact angle, $\theta$, in (2) should exactly reflect the local wettability of water on the pore walls in the GDL material. However, the contact angle in the pores is very difficult to measure, so that some early studies specified $\theta=0^{\circ}[8,9,13-19]$ in the LeverettUdell correlation. To improve the removal of liquid water, commercial carbon paper or carbon cloth GDL is generally loaded with hydrophobic materials such as PTFE (polytetrafluoroethylene) and FEP (fluorinated ethylene propylene) [62]. Based on the hydrophobic characteristics of GDL, subsequent studies adopted the contact angles greater than $90^{\circ}$, such as $\theta=92^{\circ}$ [22], $110^{\circ}$ [20], $120^{\circ}$ [24, 63], 91-120 [23], or $91-130^{\circ}$ [25].

It is noted that the contact angles adopted in above studies are all hypothetical due to lack of experimental data. Therefore, many efforts were carried out to determine the contact angle of water on GDL surface by sessile drop or capillary rise methods [64, 65]. For example, Mathias et al. [65] measured the contact angles of Toray-TGP-060 carbon paper by the sessile drop method. They found that the values were $135^{\circ}, 156^{\circ}$, and $164^{\circ}$ for carbon papers with 0 , 9, and $23 \mathrm{wt} \%$ PTFE, respectively. Unfortunately, the contact angles measured by these methods are the external contact angles, which are not the contact angles of water on the pore walls in the porous material. Gurau et al. [26] for the first time evaluated the internal contact angles by the Washburn technique and the Owens-Wendt two-parameter theory. They presented that the internal contact angle ranged from 88 to $101^{\circ}$ for water in various GDLs, which was slightly lower than that on a smooth surface of pure PTFE $\left(108^{\circ}\right)$ and much lower than the external contact angle measured on the GDL surface by the sessile drop method.

It is worth noting that hydrophobic pores and hydrophilic pores coexist in the GDLs due to the heterogeneous distribution of the loaded hydrophobic materials, and hence the pore walls of GDLs have a mixed wettability. Consequently, using a single contact angle in the Leverett-Udell correlation may be improper. In addition, when liquid plugs and/or liquid films transport in the GDL pores, a dynamic contact angle should be adopted to characterize the wettability of the pore walls [66-68]. This phenomenon adds further complexity for wettability of GDL pores. More importantly, the pore size, pore structure, and wettability of packed sands are found to be greatly different from those of real carbon paper or carbon cloth GDLs, as shown in Figure $1[37,69]$. The Leverett-Udell correlation may be intrinsically inappropriate for the GDLs even though the internal contact angle could be determined accurately. Several measurements of the liquid water distributions in GDLs using neutron radiography techniques [70, 71] and pressure drop methods [72] have shown that the PEM fuel cell two-phase model incorporated with the LeverettUdell correlation underestimates the liquid water saturation.

Since the Leverett-Udell correlation does not correctly capture the properties of porous electrodes in PEM fuel cells, it is urgent to develop a more comprehensive $p_{c}-s$ correlation. The data of capillary pressure versus saturation for various commonly used GDLs are the fundament for developing the new correlation, which have motivated many experimental and numerical investigations devoted to obtaining such data in the last decade.

\section{Measurement Methods for Capillary Pressure}

In the recent decade, researchers have developed several kinds of measurement methods for capillary pressure in GDL 


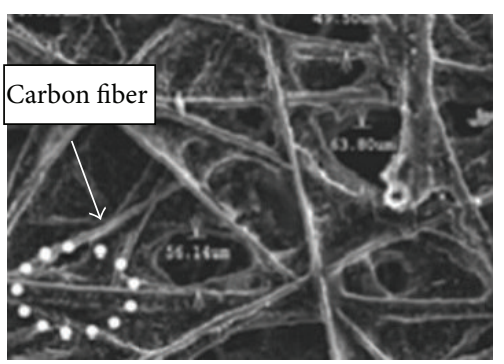

(a)

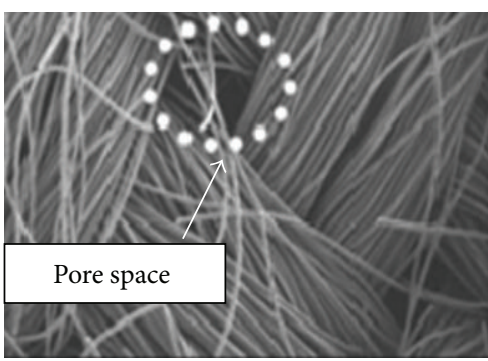

(b)

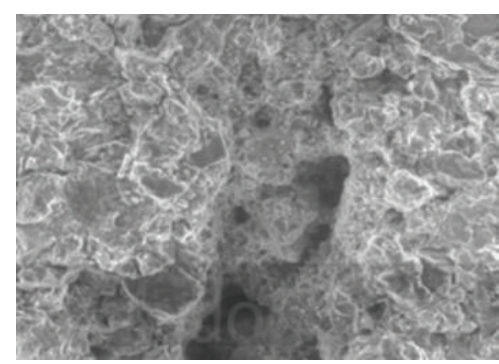

(c)

FIGURE 1: SEM images of (a) carbon paper; (b) carbon cloth; and (c) packed sands. Source: Figures 1(a) and 1(b) in [37] and Figure 1(c) in [69].

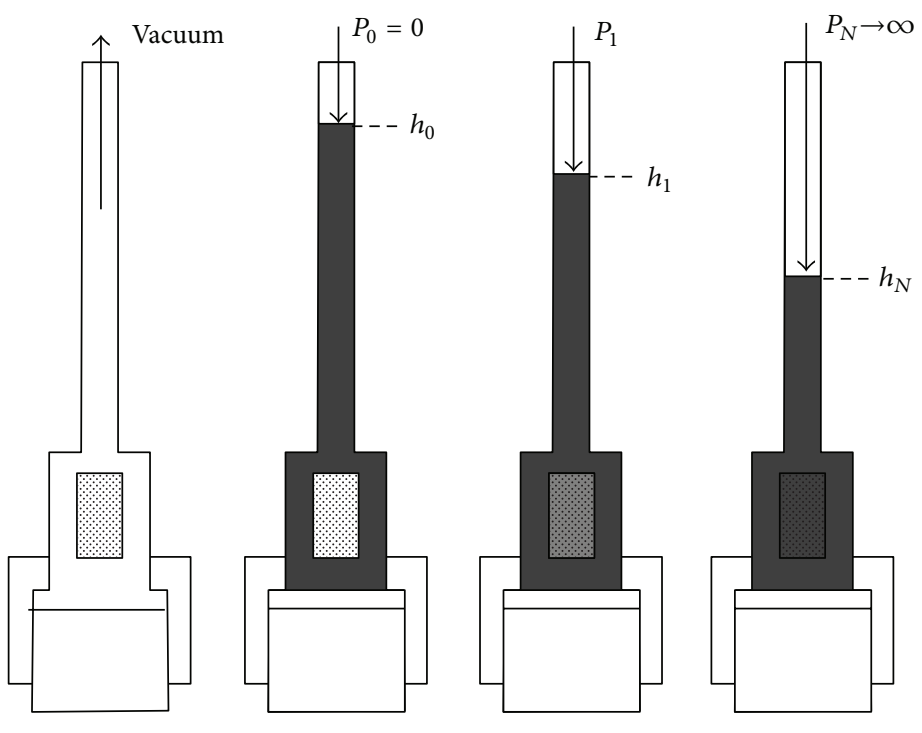

FIGURE 2: Schematic of mercury intrusion porosimetry. Source: [85].

materials. Mercury intrusion porosimetry (MIP), volumecontrolled method (VCM), method of standard porosimetry (MSP), and gas controlled porosimetry (GCP) are the most common methods. These four methods are reviewed in this section, while the other methods such as X-ray CT method and gravimetrical saturation measurement can be found in $[36,45,47,55,73,74]$.

3.1. Mercury Intrusion Porosimetry. As a development of traditional capillary pressure measurement method raised by Morrow et al. [75, 76], mercury intrusion porosimetry (MIP) was firstly used to study the morphology of the microporous layer (MPL) [77-80] and the influence of adding PTFE on the MPL [81]. Later the method was introduced to investigate the capillary property of GDL materials used in PEM fuel cell devices [82-84]. The assumption that the contact angle distribution was expressed by a normalized Gaussian distribution was raised; thus contact angles of the pores could be computed through MIP data, by taking the measured effective pore radius into consideration [48]. Also the effects of capillary property of GDL material on PEM fuel cell performance were qualitatively explained in these investigations.
In the MIP method as shown in Figure 2, the tested porous sample is placed in a glass sample tube. The sample tube is pumped into vacuum as the preparation of the measurement. Then the mercury is injected into the vacuum sample tube, with the controlled surrounding pressure increasing from $0 \mathrm{MPa}$ to an enough large value in several steps. The pressure value and the corresponding injected volume of mercury from each step are recorded and thus the capillary pressure curve can be obtained. Reference [85] has well introduced the detailed operation steps and the principle of MIP methods.

As an evaluation, the advantages of MIP are the low volatility and high surface tension of mercury, which lead to the negligible gaseous pressure, simplified sample equipment, and large measurement range of pressure [85]. Furthermore, it is worth noting that mercury is highly nonwetting in almost every GDL pore, so that MIP test cannot distinguish the hydrophobic pore and the hydrophilic pore. In the case of porous GDL materials for PEM fuel cells, MIP cannot directly provide a $p_{c}-s$ correlation corresponding to liquid water, unless several empirical assumptions are taken into consideration. 


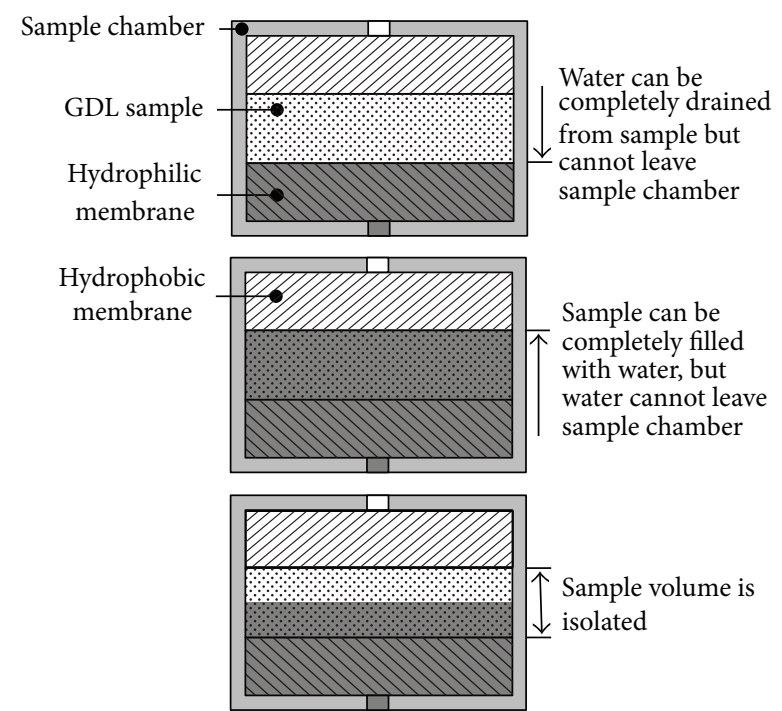

FIGURE 3: Schematic of volume-controlled method. Source: [85].

3.2. Volume-Controlled Method. Due to the disadvantages of MIP, a series of volume-controlled methods (VCM) were raised by Gostick [85]. They can be regarded as modified MIP methods which use water as the injecting liquid. However, the use of liquid water presents several new problems for measurements. The biggest one is that, unlike mercury with its low volatility, liquid water will cavitate in the tested sample [85]. As a response of the difficulty, the sample holder is designed to allow air to escape when liquid water is injected, but water cannot escape from the sample holder. In the most common design, tested sample is loaded in a sealed sample holder with two sandwiched porous membranes with opposite wettability, as shown in Figure 3. The hydrophobic membrane is a barrier to the escape of liquid water from the air gallery, while the hydrophilic membrane on the other side prevents air from escaping out of the sample holder when liquid water is injected [85]. Acosta et al. [41] obtained airwater $p_{c}-\mathcal{S}$ curve by the data tested in this designed sample holder.

As a further improvement, Fairweather et al. [42] raised volume-controlled method using the concept above. They employed a syringe to pump quantitative volumes of liquid into the sample holder and measured the pressure by transducers equipped on the piping. Briefly, in their measurements, after the liquid manifold and sample holder were filled under vacuum, the syringe pump was used to cycle water at a constant rate into and out of the sample when the liquid-gas pressure difference was measured. The method allows a time (120 s in their measurements) for capillary equilibrium before going to the next data point. Also, the processes of increasing and decreasing water saturation can be both realized, so that the curve can cover both positive and negative capillary pressure region. Sole [86] presented a similar measurement method, where the hydrophilic membrane below the sample holder was omitted and a constant rate was adopted for the
Wetting phase Nonwetting phase
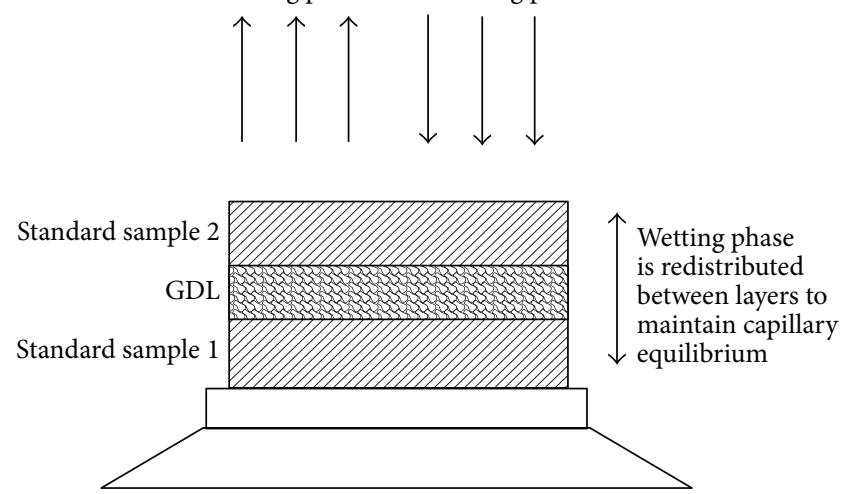

FIGURE 4: Schematic of method of standard porosimetry. Source: [85].

liquid water injection into the sample holder. Due to the lack of hydrophilic membrane, Sole [86] did not measure the $p_{c}{ }^{-s}$ correlation for water withdrawn from the sample.

In the volume-controlled method, the volume of the injected liquid is controlled to determine the saturation, which often introduces errors due to the difficulty of controlling the liquid volume. Nguyen et al. $[44,59]$ introduced an improved method which controlled liquid pressure instead of liquid volume. Thus the capillary pressure can be measured by communicating pipes connected with the sample holder.

3.3. Method of Standard Porosimetry. Method of standard porosimetry (MSP) [40] is a measurement technique developed from experimental investigations of cermet in solid oxide fuel cells [87] and Nafion membranes [88]. The schematic of the method is shown in Figure 4. The method uses the capillary equilibrium between two porous materials keeping in touch, so they have the same capillary pressure. In the design of Gostick et al. [40], two standard samples with a specific capillary pressure curve were needed. Between them one tested sample was loaded. The three sandwiched samples (the two standard samples and the one tested) were prepared by flooding them with the wetting fluid (often octane) and ensured that no air was in the pores of the samples. Then the combination of the samples was exposed to air, so that the wetting fluid would evaporate and lead to a changed saturation. The capillary pressure could be measured by periodically weighing the tested sample and standard samples.

It is worth noting that the process of MSP is also a replacement of a nonwetting phase into a material filled with wetting phase, so it can use both octane and water as working fluids, which can obtain partially useful $p_{c}-s$ curve for GDLs. The liquid water transport properties of hydrophilic pores especially can be obtained. But the MSP technique is also of limitation when used to test GDL materials. This method only scans along the direction of increasing air saturation and only for positive capillary pressure region. 


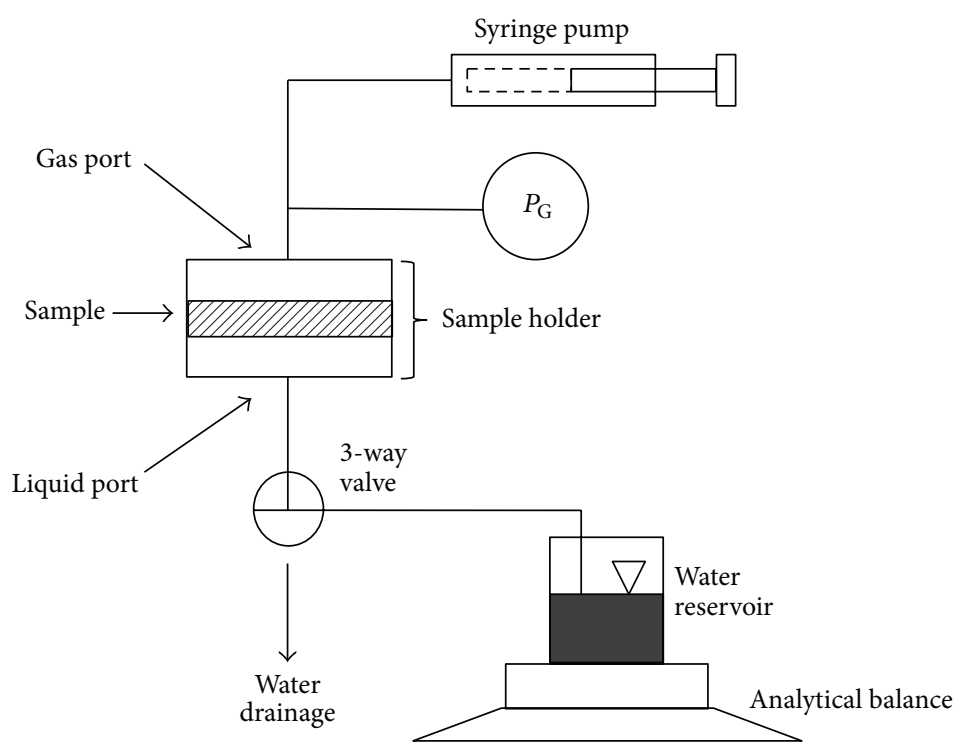

FIGURE 5: Schematic of gas controlled porosimetry. Source: [51].

As a successful application of MSP, Mench's group [3739] used this technique to investigate the capillary properties of various GDLs at the different PTFE contents, compression pressures, and temperatures. By taking these parameters into consideration, a comprehensive correlation was obtained by Mench's group, which will be reviewed in Section 5.

In the MSP measurements the liquid water saturation is changed by drying the samples in the air, which is hard to control. Gallagher et al. [46] modified the method by applying an extra suction to the sandwiched samples, so that they could control the capillary pressure directly. The modified method could measure the $p_{c}-s$ correlation for water injection and withdrawal processes.

3.4. Gas Controlled Porosimetry. Technically, MIP and MSP can partially obtain acceptable air-liquid water capillary pressures which are useful for GDL in PEM fuel cells. However, until then, the dynamic hysteresis phenomena of liquid water in porous GDL materials were not noticed because all the measurement techniques above are designed under pseudoequilibrium conditions [51]. To ensure that the measured capillary pressures can cover both positive and negative capillary pressure regions, in both scanning directions (both increasing and decreasing saturation directions), GCP method was developed by Gostick et al. [51]. In this method, as shown in Figure 5, volume of liquid water is controlled by water drainage system which is connected to a sample holder. Meanwhile, this method can control the capillary pressure in the sample by a syringe pump which can adjust the pressure of the gaseous phase. Also it achieves the injectiondrainage process of the GDL material repetitively in one measurement. Thus the dynamic hysteresis phenomena can be easily recorded.

In summary, MIP can obtain a large range of capillary pressure by simple equipment and operations; however, several empirical assumptions have to be introduced because this method cannot directly measure the capillary pressure of water. VCM is an improved method from MIP, where liquid water is used as the working fluid and the data cover both positive and negative capillary pressure regions, so that these data can be directly used to model capillary characteristics of GDLs. Unfortunately, VCM often leads to significant errors due to the difficulty of controlling the liquid volume. MSP is designed to distinguish the liquid water transport properties in hydrophilic and hydrophobic pores by simple operations, while it is only suitable for water withdrawal process. GCP can also cover both positive and negative capillary pressure regions with relatively smaller errors than VCM; however, the measure system of GCP is more complicated.

\section{New Capillary Pressure Data}

Table 1 summarizes the recent works on capillary pressure curves for commercial GDLs. Among these works, Gostick's [40, 43, 50, 51, 55-58], Mench's [37-39], Schwartz's [42, 48, 52], and Nguyen's $[44,59]$ groups did many contributions. The capillary pressure curves can be obtained by either direct measurements $[37-53,55,57-60]$ or numerical simulations $[36,45,47,53,56,57]$.

Gostick et al. [40] measured capillary pressure curves for water and octane during withdrawal from GDLs. They presented that most GDLs used in their study had almost the same fiber and pore structure, and hence the Leverett correlation (2) could provide a good description of the capillary pressure versus saturation data. Meanwhile, they thought that the contact angle could be removed from this correlation because all the samples were prepared by similar material and the capillary pressures had already been related to an air-water basis. Their results (Figure 6) indicated that when van Genuchten or Brooks-Corey type $J$ function was adopted during the fitting, the $p_{c}-s$ data of the various GDLs gathered together into a single curve reasonably well. van 
TABLE 1: Measurements and simulations of capillary pressure curves for various commercial GDL.

\begin{tabular}{|c|c|c|c|c|}
\hline Authors & Technique & GDL series & Working fluid & Pressure range $(\mathrm{MPa})$ \\
\hline $\begin{array}{l}\text { Gostick } \\
\text { et al. [40] }\end{array}$ & MSP, MIP & $\begin{array}{l}\text { SGL 10BA/10BB, Toray 090, E-Tek Cloth A, } \\
\text { Lyflex 484C/352C }\end{array}$ & Octane & $10^{-5} \sim 10$ \\
\hline $\begin{array}{l}\text { Gostick } \\
\text { et al. [43] }\end{array}$ & $\begin{array}{l}\text { Single measurement } \\
\text { of a GCP sample }\end{array}$ & SGL 10BA, Toray 090 & Water & $-0.025 \sim 0.035$ \\
\hline $\begin{array}{l}\text { Gostick } \\
\text { et al. [51] }\end{array}$ & GCP & $\begin{array}{l}\text { SGL 10AA/10BA/10CA/10DA, Toray } \\
\text { 060A/060C/090A/090C/090D/120A/120D }\end{array}$ & Water & $-0.02 \sim 0.02$ \\
\hline $\begin{array}{l}\text { Gostick } \\
\text { et al. [50] }\end{array}$ & $\begin{array}{l}\text { Single measurement } \\
\text { of a GCP sample }\end{array}$ & SGL 10BA/10BB & Water & $-0.001 \sim 0.02$ \\
\hline $\begin{array}{l}\text { Gostick } \\
\text { et al. [55] }\end{array}$ & $\mathrm{X}$-ray CT & Toray $120 \mathrm{~A} / 120 \mathrm{C} / 120 \mathrm{D}$ & Water & $-0.015 \sim 0.015$ \\
\hline Gostick [57] & $\begin{array}{l}\text { Single measurement } \\
\text { of a GCP sample, pore } \\
\text { network model }\end{array}$ & $\begin{array}{l}\text { Toray } 120 \mathrm{~A} / 120 \mathrm{C} / 060 \mathrm{~A} / 060 \mathrm{C} / 060 \mathrm{D}, \mathrm{SGL} \\
\text { 10BA/10BB }\end{array}$ & Water & $0 \sim 0.015$ \\
\hline $\begin{array}{l}\text { Gostick et al. } \\
{[56]}\end{array}$ & Pore network model & Toray 060 & Mercury & $0 \sim 0.3$ \\
\hline $\begin{array}{l}\text { Shrestha and } \\
\text { Gostick [58] }\end{array}$ & $\begin{array}{l}\text { A modified GCP with } \\
\text { a temperature } \\
\text { controller }\end{array}$ & Toray 120 with 0 and $10 \%$ PTFE & Water & $-0.025 \sim 0.025$ \\
\hline $\begin{array}{l}\text { Kumbur } \\
\text { et al. [37] }\end{array}$ & MSP & SGL 24BC/24CC/24DC, E-Tekelat $1200 \mathrm{~W}$ & Octane and water & $0.01 \sim 10$ \\
\hline $\begin{array}{l}\text { Kumbur } \\
\text { et al. [38] }\end{array}$ & MSP & SGL 24BC/24DC/10BB & Octane and water & $0.01 \sim 10$ \\
\hline $\begin{array}{l}\text { Kumbur } \\
\text { et al. [39] }\end{array}$ & MSP & SGL 24BC/24CC/24DC/10BB & Octane and water & $0.01 \sim 10$ \\
\hline $\begin{array}{l}\text { Kumbur } \\
\text { et al. [36] }\end{array}$ & $\begin{array}{l}\text { Artificial neural } \\
\text { network }\end{array}$ & SGL 24BC/24CC/24DC & None & $0.01 \sim 10$ \\
\hline $\begin{array}{l}\text { Fairweather } \\
\text { et al. [42] }\end{array}$ & $\begin{array}{l}\text { Volume-controlled } \\
\text { method }\end{array}$ & $\begin{array}{l}\text { Toray TGP-090, unsintered Avcarb P75T, } \\
\text { heat-treated Avcarb P75T }\end{array}$ & Mercury & $-0.02 \sim 0.02$ \\
\hline $\begin{array}{l}\text { Cheung } \\
\text { et al. [48] }\end{array}$ & $\begin{array}{l}\text { Volume-controlled } \\
\text { method }\end{array}$ & Toray 090 & Mercury & $-0.02 \sim 0.02$ \\
\hline $\begin{array}{l}\text { Fairweather } \\
\text { et al. [52] }\end{array}$ & $\begin{array}{l}\text { Volume-controlled } \\
\text { method }\end{array}$ & Toray 090 with $5 \% / 10 \% / 20 \% / 40 \%$ Teflon & Mercury & $-0.013 \sim 0.015$ \\
\hline $\begin{array}{l}\text { Nguyen } \\
\text { et al. [59] }\end{array}$ & Modified MSP & SGL 10AA/10BA & Water & $-0.0005 \sim 0.0003$ \\
\hline $\begin{array}{l}\text { Nguyen } \\
\text { et al. [44] }\end{array}$ & Modified MSP & SGL 10CA, Toray 060 & Water & $-0.0002 \sim 0.0005$ \\
\hline $\begin{array}{l}\text { Acosta } \\
\text { et al. [41] }\end{array}$ & Unknown & E-TekELAT-DS & Unknown & $-2 \sim 0$ \\
\hline $\begin{array}{l}\text { Koido } \\
\text { et al. [45] }\end{array}$ & $\begin{array}{l}\text { X-ray CT, pore } \\
\text { network model }\end{array}$ & Toray 060 & Water & $-0.01 \sim 0$ \\
\hline $\begin{array}{l}\text { Rensink } \\
\text { et al. [47] }\end{array}$ & $\begin{array}{l}\text { Gravimetrical } \\
\text { saturation } \\
\text { measurement, VOF }\end{array}$ & Toray 060 & Water & $0 \sim 0.05$ \\
\hline $\begin{array}{l}\text { Sole and Ellis } \\
{[60]}\end{array}$ & $\begin{array}{l}\text { Volume-controlled } \\
\text { method }\end{array}$ & Toray 090 with $0 \% / 10 \% / 20 \% / 30 \%$ PTFE & Water & $0 \sim 0.02$ \\
\hline $\begin{array}{l}\text { Gallagher } \\
\text { et al. [46] }\end{array}$ & Modified MSP & MRC, Toray 060 & Water & $0 \sim 0.025$ \\
\hline $\begin{array}{l}\text { Harkness } \\
\text { et al. [49] }\end{array}$ & $\begin{array}{l}\text { Volume-controlled } \\
\text { method }\end{array}$ & Toray 060 & Water & $-0.028 \sim 0.049$ \\
\hline $\begin{array}{l}\text { Hao and } \\
\text { Cheng [53] }\end{array}$ & $\begin{array}{l}\text { Volume-controlled } \\
\text { method, LBM }\end{array}$ & Toray 090 with 10\%/30\%PTFE & Water & $-0.015 \sim 0.015$ \\
\hline
\end{tabular}




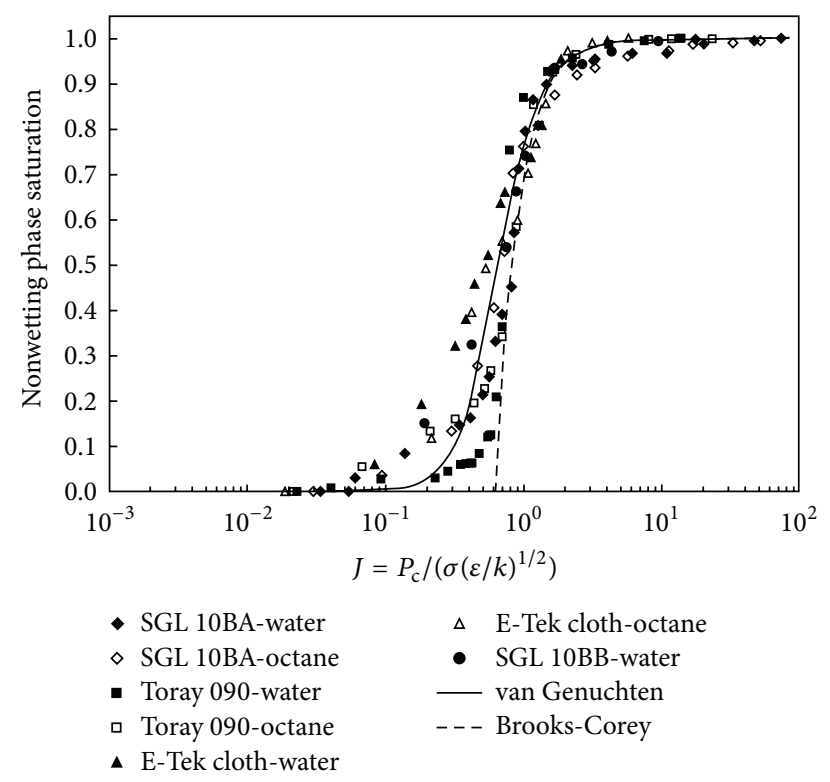

Figure 6: Comparison of experimental $J(s)$-s curves for the overall and hydrophilic pore networks with Brooks-Corey and van Genuchten models for all unimodal GDLs tested. Source: [40].

Genuchten or Brooks-Corey type $J$ function can be expressed as follows, respectively:

$$
\begin{aligned}
& s=\left(1+\left(\frac{J}{J_{c}}\right)^{n}\right)^{-m}, \\
& s=\left(\frac{J}{J_{c}}\right)^{-\lambda},
\end{aligned}
$$

where $J_{c}, \lambda, m$, and $n$ are fitted parameters.

Gostick et al. [43, 51, 55] further measured $p_{c}-s$ curves for water withdrawal and injection. They found that there existed a capillary pressure hysteresis during the loop of water injection and withdrawal $[51,55]$ and water withdrawal from any $s$ reached by water injection also resulted in hysteresis (Figure 7) [43]. Water can neither be injected into a dry GDL spontaneously nor be drained from a water-saturated GDL spontaneously. Therefore, a positive pressure is needed to compel water and air to be injected into GDLs. They proposed that adding PTFE could increase the hydrophobicity of the GDL, so that the work required for water removal was decreased. They also found that water-air $p_{c}$-s curves depended on GDL thickness, which indicated that finite size effects were nonignorable. They thought that hysteresis came from two origins $[43,51]$. Firstly, the advancing contact angle $\theta_{A}$ for water injection and receding contact angle $\theta_{R}$ for water withdrawal differed, which is referred to as the contact angle hysteresis [61]. Secondly, capillary equilibrium was achieved by irreversible meniscus transitions and depended on the history of saturation change. Fairweather et al. [42], Acosta et al. [41], Harkness et al. [49], and Gallagher et al. [46] also found the hysteresis of the $p_{c}-s$ curves during water injection into and withdrawing from GDLs. Fairweather et al. [52] further experimentally studied the effect of the Teflon loading

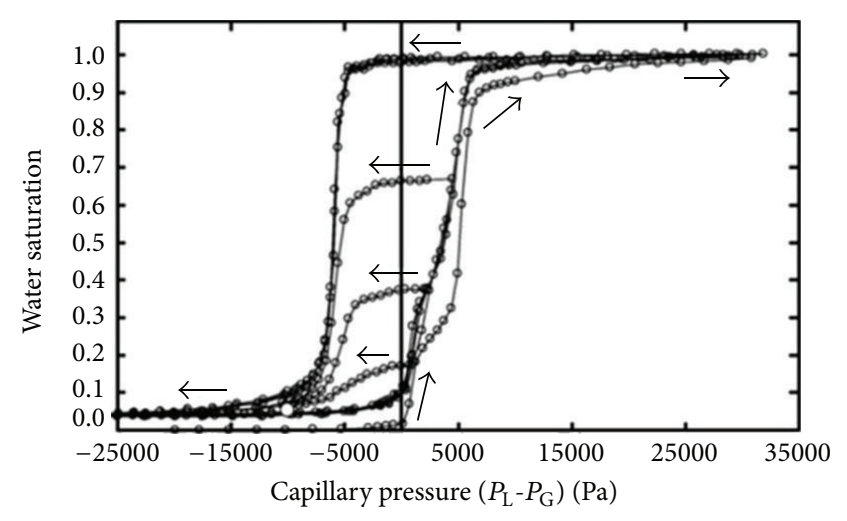

FIGURE 7: Air water capillary pressure curve for Toray 090. Source: [43].

on the $p_{c}-s$ curves. These authors added 5-40 wt $\%$ Teflon into Toray 090 carbon paper and noted hysteresis in all their tests with GDLs. Nguyen et al. $[44,59]$ measured the $p_{c}$-s curves of two GDL materials, a high-porous material of SGL 10CA and a less porous denser material by Toray 060. Somewhat surprised, these authors did not note any hysteresis, probably owing to a small range of capillary pressure studied.

Gostick et al. [50] also studied the MPL effect in PEM fuel cell operation by ex situ measurements of the capillary pressure curves. Their capillary pressure data showed that the saturation in the GDL for water breakthrough was reduced significantly from $25 \%$ to $5 \%$ in the presence of MPL. Their findings suggested that the effectiveness of the MPL might be further improved by designing them with large holes for water passage into the GDL, while leaving the microporosity dry for gas transport.

In Shrestha and Gostick's work [58], the $p_{c}-s$ curves for Toray 120 with 0 and $10 \%$ PTFE loadings were measured in the temperature range of $25-85^{\circ} \mathrm{C}$. They found that notable shifts in the capillary behavior were seen and in some cases the shifts were of the same size as PTFE addition. In untreated samples, the results suggested that GDL wettability changed with temperature once the temperature dependence of the surface tension had been accounted for. In treated samples, however, the wettability remained more or less constant with temperature.

In series works of Mench's group [37-39], the capillary pressure curves for SGL series carbon papers were tested at a large range of 5-20 wt\% PTFE loadings, at compressions of 0 , 0.6 , and 1.4 MPa, and at operating temperatures of 20,50, and $80^{\circ} \mathrm{C}$. They examined the effectiveness of the Leverett-Udell correlation and found a significant deviation of the standard Leverett function from the experimental data.

Sole and Ellis [60] measured and compared the $p_{c}-s$ curves for two kinds of representative GDL materials (one paper, one cloth), each with four different bulk loadings of PTFE $(0,10,20$, and $30 \mathrm{wt} \%)$. Their results showed that the PTFE loading had only a small influence on the capillary pressure within the pressure range normally associated with PEM fuel cell water transport. The results also showed that carbon cloth-based GDL materials required greater 
capillary pressures than paper materials to achieve significant saturation and that compression could homogenize the pore structure and the slope of the capillary pressure-saturation curve of both materials.

Besides direct experimental measurement, numerical modeling and simulations are another important way to produce data of capillary pressure versus saturation. Koido et al. [45] applied pore network model to predict the $p_{c}-s$ curve of Toray 060 GDL. They presented two reasons for the use of pore network model. Firstly, the approach did not require high computational cost because the model idealized the pore morphology and topology as a pore network composed of throats and pores. Secondly, the GDL properties, such as wettability, pore size distribution, and pore connectivity, were easily modified as parameters in the calculation. In work of Gostick et al. [56, 57], the pore network model was also used to simulate realistic water configurations generated within GDLs. The model was able to reproduce the experimental injection breakthrough saturations and had been extended to describe water condensation. Their simulations confirmed that the water saturation at breakthrough was decreased significantly when a MPL was incorporated into the GDL, agreeing with experiments. However, the simulations yielded limiting currents significantly higher than those observed in practice whether or not an MPL was present, which suggested that mass transfer resistance within the catalyst layer played an important role. Rensink et al. [47] used a volume of fluid (VOF) method to determine the two-phase behavior in a virtually created substrate. No constitutive relations were used since the liquid/gas boundary was resolved. Using the simulated liquid saturation and pressure as a function of time, they combined them to get a capillary pressure curve. The curve was compared with the Leverett-Udell correlation. The comparison showed that the best fit between VOF results and the Leverett-Udell correlation was achieved for liquid saturation below 0.2. For higher liquid saturations the LeverettUdell correlation yielded higher saturation. Hao and Cheng [53] adopted lattice Boltzmann simulation to produce capillary pressure curves in a carbon paper GDL with hydrophobic and hydrophilic pores. They compared the simulated and measured $p_{c}-s$ curves for water withdrawal and injection. The results indicated that $p_{c}-s$ curves for the withdrawal and injection agreed well with those measured by experiment, which demonstrated the coexistence of hydrophobic and hydrophilic pores in the carbon paper GDLs treated by PTFE. They thought that the $p_{c}-s$ curves fitted by lattice Boltzmann simulations provided better predictions in carbon paper GDLs with homogeneous wettability and porosity, compared with the standard Leverett-Udell correlation.

\section{New $p_{c}-s$ Correlations}

The aim of measurements and simulations for capillary pressure curves is to develop a new $p_{c}{ }^{-s}$ correlation for commercial GDLs, because such correlation is imperative to the understanding and prediction of two-phase transport phenomenon in the porous electrodes of PEM fuel cells. Up to now, large amount of capillary pressure data for GDLs commonly used in the PEM fuel cell has been reported, which make it possible to develop the new $p_{c}-s$ correlations. In recent years, some researchers were devoted to developing new $p_{c}-s$ correlations based on these available capillary pressure data, and the main progresses are summarized as follows.

It was a very challenging task to propose an overall new $p_{c}-s$ correlation, hence, a majority of researchers adopted the simplest way to model $p_{c}-s$ correlation. The capillary pressure was assumed to be a function of saturation only; that is, $p_{c}=$ $f(s)$. The function form of $f(s)$ was chosen arbitrarily. Nam and Kaviany [89] used a linear function:

$$
p_{c}=c s
$$

Lin and van Nguyen [90] also adopted the same linear $p_{c}-s$ correlation. Later, more complex function such as the polynomial was used. For example, Kumbur et al's function was [33]

$$
p_{c}=c_{1} s+c_{2} s^{2}
$$

Sole and Ellis's function was [60]

$$
\frac{d p_{c}}{d s}=c_{0}+c_{1} s+c_{2} s^{2}+c_{3} s^{3}+c_{4} s^{4}+c_{5} s^{5}+c_{6} s^{6}
$$

And Wang et al.s function was [35]

$$
p_{c}=c_{0}+c_{1} s+c_{2} s^{2}+c_{3} s^{3}
$$

Ye and van Nguyen adopted an exponential form [34]:

$$
p_{c}=d_{1} \exp \left(-a_{1}[s-c]\right)-d_{2} \exp \left(a_{2}[s-c]\right)+b \text {. }
$$

Acosta et al. [41] used a semiexponential and semipolynomial form:

$$
\begin{aligned}
p_{c}= & a_{1} \exp \left(b_{1} s+c_{1}\right) \\
& +d_{1}(1-s) \text { for the imbibition process } \\
p_{c}= & a_{2} \exp \left(b_{2} s+c_{2}\right)+d_{2}(1-s) \\
& +\frac{e_{2}}{s} \text { for the drainage process. }
\end{aligned}
$$

The parameters in (5)-(10b) can be determined by fitting the experimentally measured $p_{c}-s$ data. It should be noted that the above correlations $((5)-(10 b))$ are less meaningful physically and this kind of empirical correlations is subjected to a great limitation that only the fitted data agree with the $p_{c}-s$ correlation.

Through a bundle of capillaries model, Cheung et al. [48] proposed a method to deconvolute the effects of pore wettability and structure from $p_{c}-s$ measurements. Their study firstly reported representative distributions of contact angle which described the internal wettability in GDLs for both liquid and gas injection and agreed with experimentally measured $p_{c}-s$ data. The model considered the surface roughness and chemical heterogeneity of the GDLs by using a single Gaussian distribution of the contact angle based on 
the Cassie-Baxter equation. The $p_{c}-s$ model can be expressed as

$$
\begin{aligned}
s\left(p_{c, k}\right)=\frac{\sum_{i=1}^{N} \sum_{j=1}^{M} \Delta V\left(R_{\text {eff }}\right) \psi\left(\theta_{j}\right) F}{\sum_{i=1}^{N} \Delta V\left(R_{\text {eff }}\right)} \\
\begin{cases}F=1 & \text { if } p_{c}\left(R_{\text {eff }}, \theta_{j}\right)<p_{c, k} \\
F=0 & \text { if } p_{c}\left(R_{\text {eff }}, \theta_{j}\right)>p_{c, k},\end{cases}
\end{aligned}
$$

where $R_{\text {eff }}$ is the effective pore radius, $N$ is the total number of pores, $M=181$ corresponds to $\theta_{j}$ varying from 0 to $180^{\circ}$, and $\Delta V$ is the incrementally intruded volume at each applied pressure of mercury. Although Cheung et al's work is a useful try, their $p_{c}-s$ model is hard to be utilized in PEM fuel cell two-phase modeling because the model needs detailed structure parameters of pores such as the pore size distribution.

Though the Leverett-Udell correlation is not suitable for GDLs in PEM fuel cells, it still has some advantages where the information of capillary force $(\sigma)$ and pore structure ( $\varepsilon$ and $k_{p}$ ) is included. Thus, a further improved way is to keep the form of the Leverett function; however, the $J$ function needs to be refitted to match the experimentally measured $p_{c}-s$ data of GDLs. For example, Gostick et al. [40] substituted the van Genuchten or Brooks-Corey type $J$ function for the Udell $J$ function. The modified Leverett function was found to agree with the measured $p_{c}-s$ data for the seven GDLs. In Gostick et al's correlation [40], the factor $\cos \theta$ was removed, but the van Genuchten or Brooks-Corey type $J$ function did not include the wettability parameter. Regarding this drawback, Mench's group [37-39] took the weight percentage of hydrophobic materials as the wettability parameter and incorporated it into $J$ function. The new $J$ function was referred to as $K$ function. Further, the effects of compression pressure and temperature were also incorporated into their correlation. Finally, the correlation proposed by Mench's group for SGL $10 \mathrm{BB}$ and SGL 24 series carbon papers is expressed as follows, respectively:

$$
\begin{aligned}
p_{c} & =\left(\frac{293}{T^{6}}\right) \sigma(T) 2^{0.4 C}\left(\left(\frac{0.9}{1+\left(-0.0046 C^{2}\right)+0.0843 C}+0.1\right) \frac{\varepsilon}{k_{p}}\right)^{1 / 2} K(s) \\
p_{c} & =\left(\frac{293}{T^{6}}\right) \sigma(T) 2^{0.4 C}\left(\left(\frac{0.9}{1+\left(-0.0083 C^{2}\right)+0.0911 C}+0.1\right) \frac{\varepsilon}{k_{p}}\right)^{1 / 2} K(s) \\
K\left(s_{\mathrm{nw}}\right) & = \begin{cases}(\mathrm{wt} \%)\left[0.0469-0.00152(\mathrm{wt} \%)-0.0406 s^{2}+0.143 s^{3}\right]+0.0561 \ln s, & 0<s \leq 0.50 \\
(\mathrm{wt} \%)\left[1.534-0.0293(\mathrm{wt} \%)-12.86 s^{2}+18.824 s^{3}\right]+3.416 \ln s, & 0.50<s \leq 0.65 \\
(\mathrm{wt} \%)\left[1.7-0.0324(\mathrm{wt} \%)-14.1 s^{2}+20.9 s^{3}\right]+3.79 \ln s, & 0.65<s<1.00,\end{cases}
\end{aligned}
$$

where $C$ is the compression pressure. This correlation can be used to predict the influences of liquid saturation, hydrophobic additive loading, uncompressed porosity, compression pressure, and operating temperature on the capillary pressure of GDLs, showing considerable further improvement over the traditional Leverett correlation.

\section{Use of New $p_{c}$-s Correlation}

The measurement of capillary pressure and the construction of $p_{c}-s$ correlation are to serve the PEM fuel cell twophase modeling. In the recent years, some research tried to incorporate the new developed $p_{c}$-s correlation into the PEM fuel cell two-phase model [33-36, 91, 92]. These studies can be divided into two categories. One is to investigate the effectiveness of the Leverett-Udell correlation to describe two-phase transport in the porous electrodes [33] or full cell [35] by comparing the local transport phenomena and cell polarization characteristics predicted by the experimentally fitted $p_{c}-s$ correlation and Leverett-Udell correlation. The other focuses on the effect of the new $p_{c}-s$ correlation on the reactants and liquid water distributions, as well as the cell performance at various operation conditions or when various GDLs are used in cells $[34,91,92]$.

Mench's group [33] for the first time tried to evaluate the effectiveness of the standard Leverett-Udell correlation to characterize the capillary flow in GDL with mixed wettability. They derived an empirical $p_{c}$-s correlation (6) by fitting the experimental data measured by Gostick et al. [40]. The empirically derived $p_{c}-s$ correlation was then integrated into a two-dimensional analytical model framework in order to evaluate the difference of the liquid saturation distributions in the GDL, which were, respectively, simulated by the derived correlation and the Leverett-Udell correlation. The results showed that the Leverett-Udell correlation consistently overestimated the GDL saturation values, as compared to those predicted by the empirically derived $p_{c}-s$ correlation (Figure 8). The remarkable difference between the predicted saturation distributions demonstrated that use of the standard Leverett-Udell correlation was indeed improper for describing the capillary characteristics in GDLs, and hence development of a modified correlation applicable for porous electrodes of PEM fuel cells was critically required.

Wang et al. [35] carried out a similar comparative study; however, they extended the comparison to the full cell by 


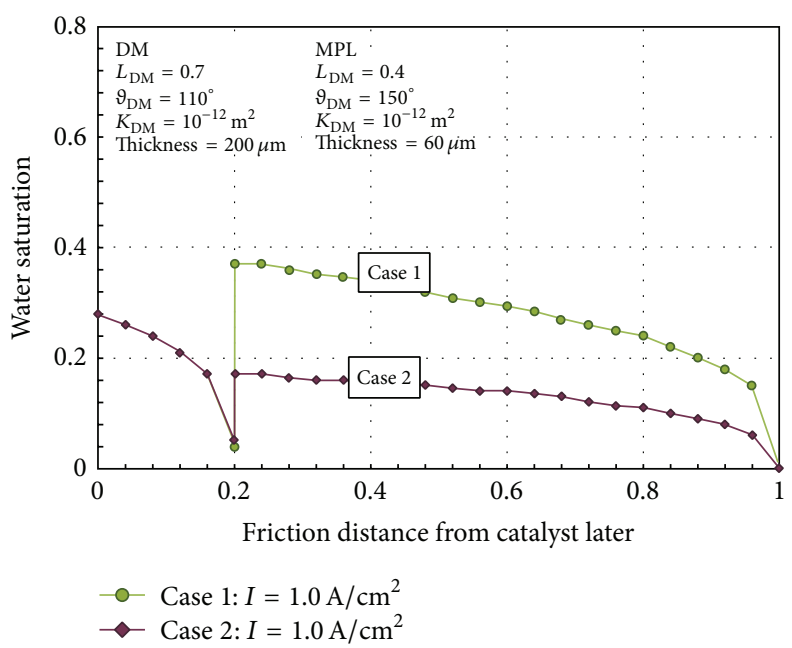

FIGURE 8: Predicted saturation profiles for Case 1 (using standard Leverett-Udell correlation) and Case 2 (using empirical curve-fit) for $200 \mu \mathrm{m}$ GDL material and the net water transport coefficient value of 0.5 at current density $1.0 \mathrm{~A} \mathrm{~cm}^{-2}$. Source: [33].

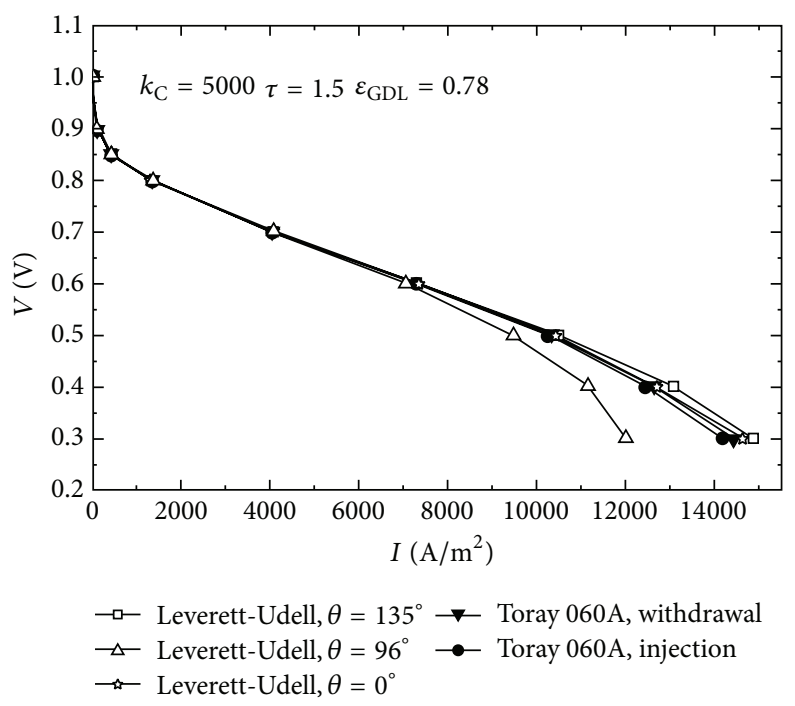

Figure 9: Polarization curves of fuel cells for various $p_{c}-s$ correlations. Sources: [35].

using a three-dimensional, nonisothermal, and two-phase fuel cell model. Key physical and chemical processes occurring in the cell were taken into account, and the experimentally fitted $p_{c}-s$ correlation and the standard LeverettUdell correlation were incorporated into the same full cell model, respectively. The cell performances simulated by the two models were evaluated at GDL tortuosity of 1.5 and 2.5 , GDL porosity of 0.6 and 0.9 , and coefficient of water vapor condensation rate of $500 \mathrm{~s}^{-1}$ and $5000 \mathrm{~s}^{-1}$. Their results (Figure 9) showed that the standard Leverett-Udell correlation with $\theta=96^{\circ}$ predicted a far worse cell performance than those with $\theta=0^{\circ}$ and $\theta=135^{\circ}$, which contradicted with the experimental observations. Thus, introduction of the factor " $\cos \theta$ " into the standard Leverett-Udell correlation could not capture the influence of wettability on the capillary pressure. The Leverett-Udell correlation with $\theta=135^{\circ}$ could predict a cell performance close to that predicted by the experimentally fitted $p_{c}-s$ correlation. However, this contact angle was far higher than the actual values of $88-101^{\circ}$; as a result, the liquid water saturation in the GDL for $\theta=135^{\circ}$ was quite different from that for an actual angle and hence deviated from the experimental saturation. They proposed that quantitative modeling adopting the standard LeverettUdell correlation was not suggested. Nevertheless, PEM fuel cell model with the standard Leverett-Udell correlation could qualitatively estimate the cell performance.

Nguyen should be the first person who pointed out the inappropriateness of the Leverett-Udell correlation for GDLs of PEM fuel cells as early as 2001 [91]. Later, Ye and van Nguyen [34] incorporated experimentally measured capillary pressure functions into a single-domain, three-dimensional, and two-phase transport model to evaluate liquid water distribution in the porous electrode of a PEM fuel cell with parallel channels. Their results showed that the liquid 


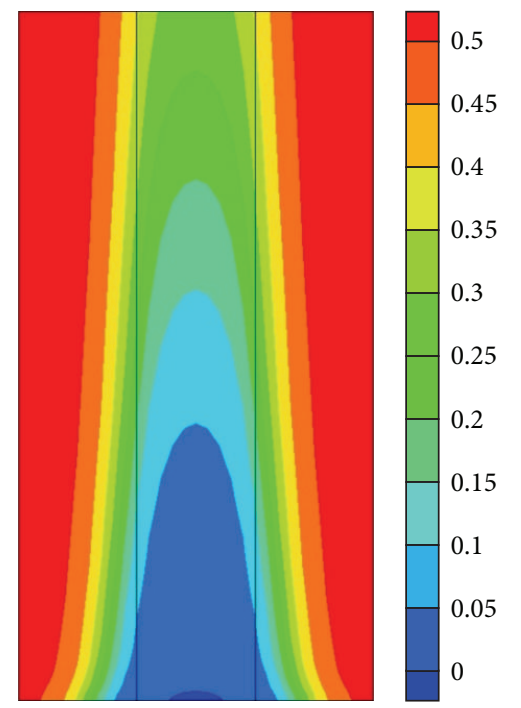

(a)

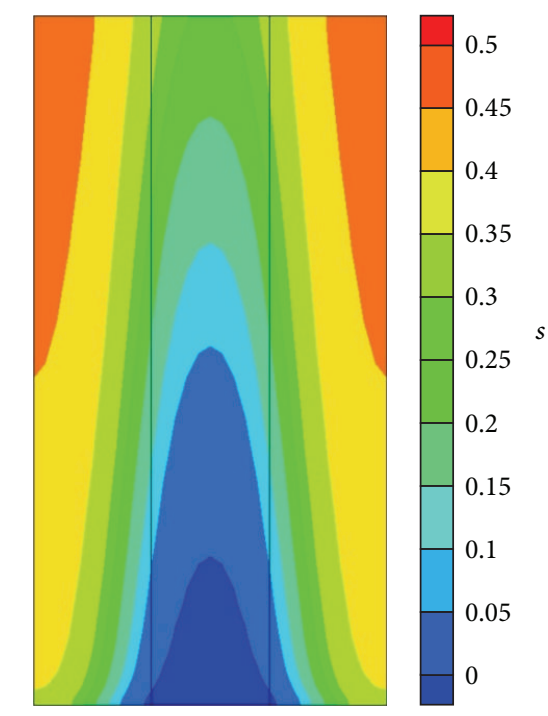

(b)

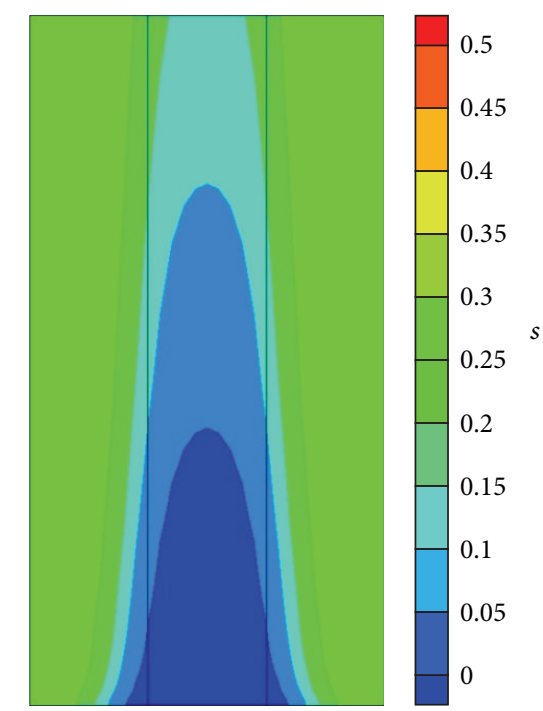

(c)

FIGURE 10: Saturation distributions on the cathode GDL-CL interface for SGL 24 series treated with different PTFE load at operating voltage of 0.3 V: (a) SGL 24BC, 5\% PTFE; (b) SGL 24CC, 10\% PTFE; (c) SGL 24DC, 20\% PTFE. Source: [92].

water distribution was lower under the rib than that under the channel in the cathode catalyst layer for high current densities. In the cathode GDL, however, the liquid water distribution was higher under the rib than that under the channel. The average water saturation levels were insensitive to current density and fell in the range of $0.4-0.5$ in the catalyst layer and $0.2-0.3$ in the GDL at high current densities. With more reliable $p_{c}-s$ correlation, liquid water distribution showed reasonable values and a trend without artificially introduced boundary conditions on the interface between the cathode channel and GDL.

More recently, Wang and Si [92] incorporated Mench's $p_{c}-s$ correlation with $K(s)$ function into a three-dimensional, nonisothermal, and two-phase model of PEM fuel cell to investigate the effects of the PTFE content, MPL, and compression pressure for two GDL series (SGL 10 and SGL 24) on the liquid water and oxygen transport and cell performance for a parallel flow field fuel cell. Restated that Mench's $p_{c}-s$ correlation retains the factor of $\left(\varepsilon / k_{p}\right)^{0.5}$ used in Leverett function, because this factor characterizes the effects of the porous structure and surface tension between gaseous and liquid phases on the liquid water distribution. Meanwhile, Mench's $p_{c}-s$ correlation removes the factor of $\cos \theta$ based on the fact that a single contact angle cannot describe the mixed wettability of porous electrodes. Furthermore, $K(s)$ function in Mench's $p_{c}-s$ correlation is derived based on fitting a variety of experimentally measured $p_{c}-s$ data for various commercial GDLs. During the fitting, the key parameters affecting the liquid water transport in the porous electrodes, such as content of hydrophobic materials, MPL, compression pressure, and temperature, are all taken into account in the $p_{c}{ }^{-s}$ correlation. Therefore, Mench's $p_{c}-s$ possesses a good versatility. It can be expected that a two-phase PEM fuel cell model incorporated with this correction will describe twophase transport phenomena in the pores of porous electrodes more reasonably.
The effects of the content of PTFE material, compression pressure, and MPL on the liquid water distribution are shown in Figures 10-12, respectively [92]. Larger content of hydrophobic materials can enhance the hydrophobicity of the porous electrode, causing the liquid water to be expelled more easily from the pores. Figure 10 shows that SGL 24BC with 5\% PTEF has the highest saturation, followed by the SGL 24CC with 10\% PTFE and the SGL 24DC with 20\% PTFE. After introducing Mench's $p_{c}-s$ correlation, the two-phase model could predict reasonably that increasing the content of the hydrophobic materials could help to expel the liquid water from the pores. However, the conventional LeverettUdell correlation characterizes the content of hydrophobic materials through contact angle; larger content corresponds to larger contact angle. The study of Wang et al. [35] indicated that the cell performance with the contact angle of $0^{\circ}$ was superior to that of $96^{\circ}$; obviously, the LeverettUdell correlation could not really reflect the effect of the content of hydrophobic materials. Similarly, the two-phase model based on Mench's $p_{c}-s$ correlation indicated that larger compression pressure led to some pores to be collapsed, which decreases the porosity and deteriorates the liquid water removal capability. As a result, a larger saturation appears in the porous electrode (Figure 11). The effect of the MPL on the liquid water removal can also be studied by incorporating Mench's $p_{c}-s$ correlation into the two-phase model. Figure 12 shows that the capability of liquid water removal in the porous electrode is enhanced when MPL were introduced between the catalyst layer and GDL, which corresponds to the lower saturation. This agrees well with the experimental reports.

\section{Closing Remarks}

Modeling and simulations have been becoming powerful tools for performance prediction and design optimization of 


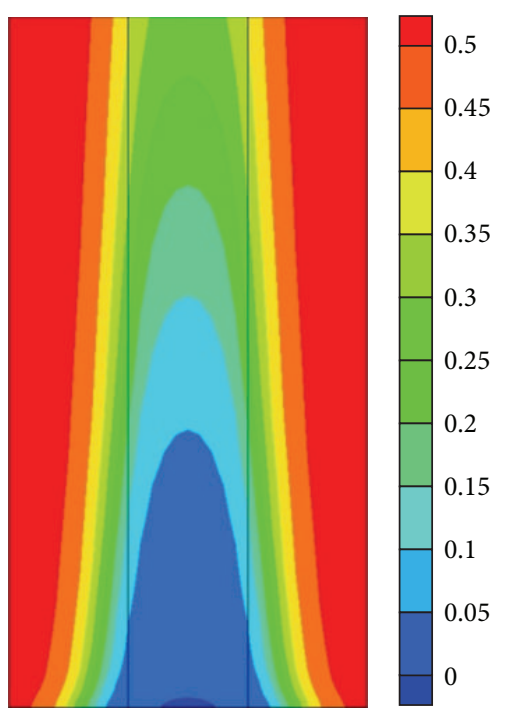

(a)

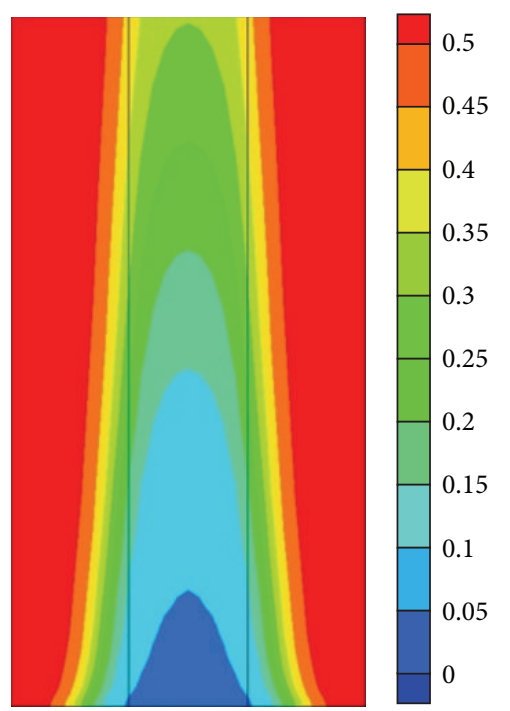

(b)

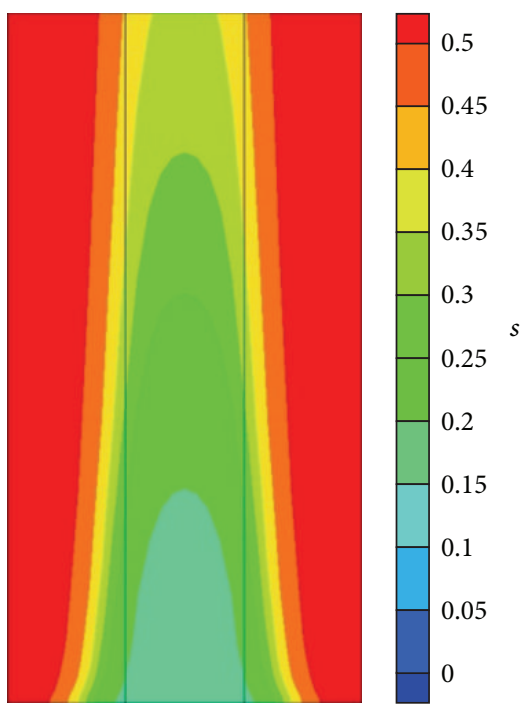

(d)

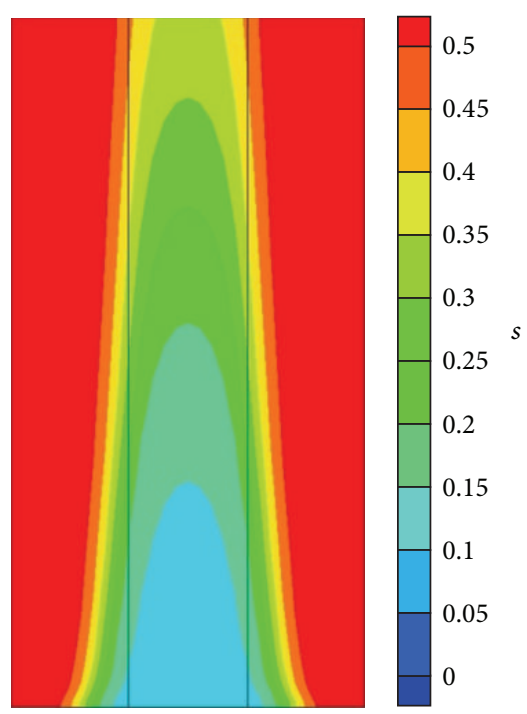

(c)

FIGURE 11: Saturation distributions on the cathode GDL-CL interface for SGL 24BC treated with different compression pressures at operating voltage of $0.3 \mathrm{~V}$ : (a) $1 \mathrm{MPa}$; (b) $2 \mathrm{MPa}$; (c) $3 \mathrm{MPa}$; (d) $4 \mathrm{MPa}$. Source: [92].

PEM fuel cells, which proposes an urgent requirement for developing an accurate porous electrode two-phase model for fuel cells. For the porous electrode modeling based on the volume-average method, Wang et al. $[12,13]$ introduced a correlation to relate the pressure difference between gaseous and liquid phases in the porous electrode pores with the local saturation by means of a capillary pressure concept. The introduction of the $p_{c}-s$ correlation leads to the fact that it is not necessary to focus on the complex interactions between the gaseous and liquid phases in the pores, which greatly simplifies the two-phase modeling for the porous electrodes and becomes the main method for the current two-phase modeling for fuel cells.

As the reason of the extremely inadequate experimental data of the capillary pressure for porous GDL, Wang et al. introduced the Leverett-Udell correlation which was fitted from the experimental data of packed sands into the modeling for PEM fuel cells. The recent studies indicated that this correlation could not cover the experimental data of capillary pressure versus saturation for the commercial used GDLs well. This motivated more and more researchers to measure the capillary pressure for various GDLs. A massive published experimental data makes it possible to propose a new $p_{c}-s$ correlation. The representative work is the correlation proposed by Mench's group. However, the experiments showed that there existed a hysteresis of capillary pressure between water withdrawal with $p_{c}>0$ and water injection with $p_{c}<0$, and water withdrawal from any $s$ reached by water injection also led to the hysteresis. The hysteresis means that the $p_{c}-s$ curve for water injection does not coincide with that for water withdrawal. In the real porous electrodes, the withdrawal or injection of the water in the local pore is determined by 


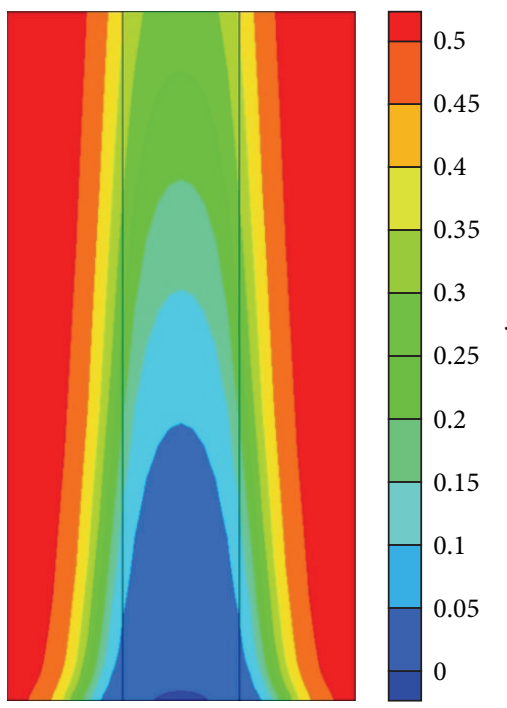

(a)

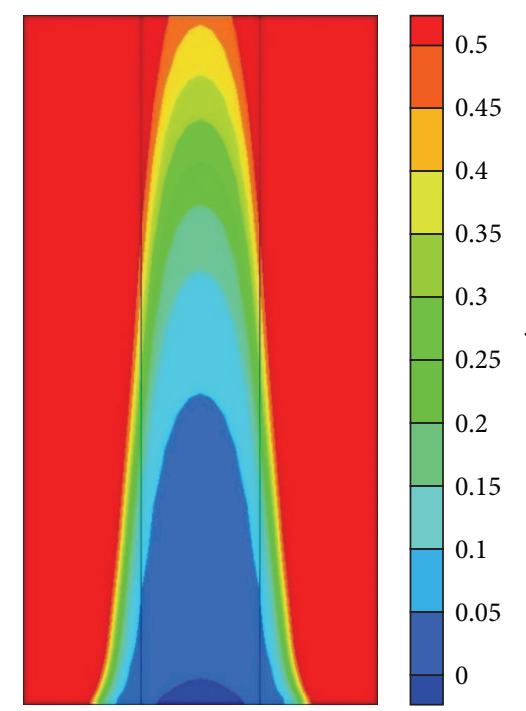

(b)

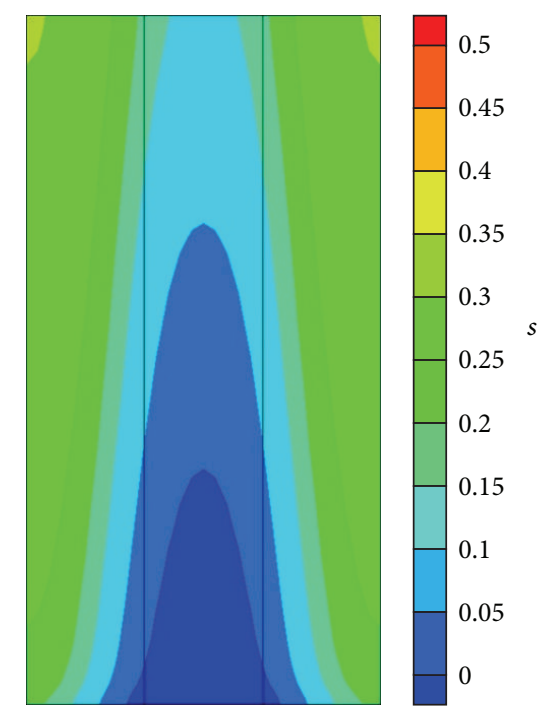

(c)

FIGURE 12: Saturation distributions on the cathode GDL-CL interface at operating voltage of $0.3 \mathrm{~V}$ for different treated GDLs: (a) SGL 24BC, 5\% PTFE with MPL; (b) SGL 24BC, 5\% PTFE without MPL; (c) SGL 10BB with MPL. Source: [92].

the local pressure difference between the gaseous and liquid phases. However, the correlation proposed by Mench's group only can describe the withdrawal process. Thus, it is necessary to develop a $p_{c}-s$ correlation which can be applicable to both withdrawal and injection processes.

In addition, the real gas-liquid interface in the pores of porous electrodes cannot be considered based on the current volume-average method. The introduction of $p_{c}-s$ correlation simplifies the treatment of the complex interactions between liquid and gaseous phases and makes it possible to carry out the two-phase modeling of porous electrodes. However, it could not capture the real transport and distributions of the two phases in the pores of porous electrodes. As a result, developing of new two-phase modeling method based on the real porous structure is the key point in the immediate future. Although it may be a great challenge to develop such a model, fortunately, some researchers have tried to model the two-phase transport in the real porous electrodes by means of lattice Boltzmann method (LBM). The next most pressing problem is to couple two-phase transport with other physical and chemical phenomena occurring in porous electrodes such as the electrochemical reactions, conductions of electron and proton, and electric osmosis. A conceivable way is the coupled LBM-CFD (computational fluid dynamics) method. Once this kind of models is constructed, the $p_{c}-s$ correlation will no longer be needed, and the phase distributions of liquid and gaseous phases in the pores of porous electrodes and the complex interactions between the two phases can be simulated directly, which makes developing a more realistic water management strategy become more believable.

\section{Conflict of Interests}

The authors declare that there is no conflict of interests regarding the publication of this paper.

\section{Acknowledgments}

This study was partially supported by the National Natural Science Foundation of China (no. 51276060), the 111 Project (no. B12034), Program for New Century Excellent Talents in University (no. NCET-11-0635), and the Fundamental Research Funds for the Central Universities (no. 13ZX13).

\section{References}

[1] C.-Y. Wang, "Fundamental models for fuel cell engineering," Chemical Reviews, vol. 104, no. 10, pp. 4727-4765, 2004.

[2] X.-D. Wang, Y.-Y. Duan, and W.-M. Yan, "Novel serpentinebaffle flow field design for proton exchange membrane fuel cells," Journal of Power Sources, vol. 173, no. 1, pp. 210-221, 2007.

[3] X.-D. Wang, Y.-Y. Duan, and W.-M. Yan, "Numerical study of cell performance and local transport phenomena in PEM fuel cells with various flow channel area ratios," Journal of Power Sources, vol. 172, no. 1, pp. 265-277, 2007.

[4] H.-C. Liu, W.-M. Yan, and X.-D. Wang, "Effects of flow channel area ratio on local transport characteristics and cell performance of 3D PEMFCs," Journal of the Electrochemical Society, vol. 154, no. 12, pp. B1338-B1348, 2007.

[5] H. Li, Y. Tang, Z. Wang et al., "A review of water flooding issues in the proton exchange membrane fuel cell," Journal of Power Sources, vol. 178, no. 1, pp. 103-117, 2008.

[6] W. Q. Tao, C. H. Min, X. L. Liu, Y. L. He, B. H. Yin, and W. Jiang, "Parameter sensitivity examination and discussion of PEM fuel cell simulation model validation. Part I. Current status of modeling research and model development," Journal of Power Sources, vol. 160, no. 1, pp. 359-373, 2006.

[7] X.-D. Wang, J.-L. Xu, and D.-J. Lee, "Parameter sensitivity examination for a complete three-dimensional, two-phase, non-isothermal model of polymer electrolyte membrane fuel cell," International Journal of Hydrogen Energy, vol. 37, no. 20, pp. 15766-15777, 2012. 
[8] X.-D. Wang, Y.-Y. Duan, W.-M. Yan, and F.-B. Weng, "Effect of humidity of reactants on the cell performance of PEM fuel cells with parallel and interdigitated flow field designs," Journal of Power Sources, vol. 176, no. 1, pp. 247-258, 2008.

[9] X.-D. Wang, Y.-Y. Duan, W.-M. Yan, and X.-F. Peng, "Local transport phenomena and cell performance of PEM fuel cells with various serpentine flow field designs," Journal of Power Sources, vol. 175, no. 1, pp. 397-407, 2008.

[10] W.-M. Yan, X.-D. Wang, D.-J. Lee, X.-X. Zhang, Y.-F. Guo, and A. Su, "Experimental study of commercial size proton exchange membrane fuel cell performance," Applied Energy, vol. 88, no. 1, pp. 392-396, 2011.

[11] W. M. Yan, X. D. Wang, S. S. Mei, X. F. Peng, Y. F. Guo, and A. Su, "Effects of operating temperatures on performance and pressure drops for a $256 \mathrm{~cm}^{2}$ proton exchange membrane fuel cell: an experimental study," Journal of Power Sources, vol. 185, no. 2, pp. 1040-1048, 2008.

[12] C. Y. Wang, Z. H. Wang, and Y. Pan, "Two-phase transport in proton exchange membrane fuel cells," in Proceedings of ASME Heat Transfer Division, vol. 364, pp. 351-357, November 1999.

[13] Z. H. Wang, C. Y. Wang, and K. S. Chen, “Two-phase flow and transport in the air cathode of proton exchange membrane fuel cells," Journal of Power Sources, vol. 94, no. 1, pp. 40-50, 2001.

[14] E. F. Medici and J. S. Allen, "Existence of the phase drainage diagram in proton exchange membrane fuel cell fibrous diffusion media," Journal of Power Sources, vol. 191, no. 2, pp. 417-427, 2009.

[15] L. X. You and H. T. Liu, "A two-phase flow and transport model for the cathode of PEM fuel cells," International Journal of Heat and Mass Transfer, vol. 45, no. 11, pp. 2277-2287, 2002.

[16] S. Mazumder and J. V. Cole, "Rigorous 3-D mathematical modeling of PEM fuel cells II. Model predictions with liquid water transport," Journal of the Electrochemical Society, vol. 150, no. 11, pp. A1510-A1517, 2003.

[17] H. Sun, H. Liu, and L.-J. Guo, "PEM fuel cell performance and its two-phase mass transport," Journal of Power Sources, vol. 143, no. 1-2, pp. 125-135, 2005.

[18] M. Vynnycky, "On the modelling of two-phase flow in the cathode gas diffusion layer of a polymer electrolyte fuel cell," Applied Mathematics and Computation, vol. 189, no. 2, pp. 15601575, 2007.

[19] A. Su, Y. M. Ferng, W. T. Chen, C. H. Cheng, F. B. Weng, and C. Y. Lee, "Investigating the transport characteristics and cell performance for a micro PEMFC through the micro sensors and CFD simulations," International Journal of Hydrogen Energy, vol. 37, no. 15, pp. 11321-11333, 2012.

[20] Y. Wang and C.-Y. Wang, "A nonisothermal, two-phase model for polymer electrolyte fuel cells," Journal of the Electrochemical Society, vol. 153, no. 6, pp. A1193-A1200, 2006.

[21] P. Zhou and C. W. Wu, "Numerical study on the compression effect of gas diffusion layer on PEMFC performance," Journal of Power Sources, vol. 170, no. 1, pp. 93-100, 2007.

[22] H. Ju, G. Luo, and C.-Y. Wang, "Probing liquid water saturation in diffusion media of polymer electrolyte fuel cells," Journal of the Electrochemical Society, vol. 154, no. 2, pp. B218-B228, 2007.

[23] M.-H. Chang, F. L. Chen, and H.-S. Teng, "Effects of two-phase transport in the cathode gas diffusion layer on the performance of a PEMFC," Journal of Power Sources, vol. 160, no. 1, pp. 268$276,2006$.

[24] G. L. He, Y. Yamazaki, and A. Abudula, "A three-dimensional analysis of the effect of anisotropic gas diffusion layer(GDL) thermal conductivity on the heat transfer and two-phase behavior in a proton exchange membrane fuel cell(PEMFC)," Journal of Power Sources, vol. 195, no. 6, pp. 1551-1560, 2010.

[25] J. H. Chun, K. T. Park, D. H. Jo, S. G. Kim, and S. H. Kim, "Numerical modeling and experimental study of the influence of GDL properties on performance in a PEMFC", International Journal of Hydrogen Energy, vol. 36, no. 2, pp. 1837-1845, 2011.

[26] V. Gurau, M. J. Bluemle, E. S. De Castro, Y.-M. Tsou, J. A. Mann Jr., and T. A. Zawodzinski Jr., "Characterization of transport properties in gas diffusion layers for proton exchange membrane fuel cells. 1. Wettability (internal contact angle to water and surface energy of GDL fibers)," Journal of Power Sources, vol. 160, no. 2, pp. 1156-1162, 2006.

[27] W.-C. Weng, W.-M. Yan, H.-Y. Li, and X.-D. Wang, "Numerical simulation of cell performance in proton exchange membrane fuel cells with contracted flow field design," Journal of the Electrochemical Society, vol. 155, no. 9, pp. B877-B886, 2008.

[28] X. D. Wang, Y. Y. Duan, W. M. Yan, and X. F. Peng, "Effects of flow channel geometry on cell performance for PEM fuel cells with parallel and interdigitated flow fields," Electrochimica Acta, vol. 53, no. 16, pp. 5334-5343, 2008.

[29] W.-M. Yan, H.-Y. Li, P.-C. Chiu, and X.-D. Wang, "Effects of serpentine flow field with outlet channel contraction on cell performance of proton exchange membrane fuel cells," Journal of Power Sources, vol. 178, no. 1, pp. 174-180, 2008.

[30] X.-D. Wang, Y.-X. Huang, C.-H. Cheng et al., "An inverse geometry design problem for optimization of single serpentine flow field of PEM fuel cell," International Journal of Hydrogen Energy, vol. 35, no. 9, pp. 4247-4257, 2010.

[31] M. C. Leverett, "Capillary hehavior in porous solids," Society of Petroleum Engineers, vol. 142, pp. 152-169, 1941.

[32] K. S. Udell, "Heat transfer in porous media considering phase change and capillarity-the heat pipe effect," International Journal of Heat and Mass Transfer, vol. 28, no. 2, pp. 485-495, 1985.

[33] E. C. Kumbur, K. V. Sharp, and M. M. Mench, "On the effectiveness of Leverett approach for describing the water transport in fuel cell diffusion media," Journal of Power Sources, vol. 168, no. 2, pp. 356-368, 2007.

[34] Q. Ye and T. van Nguyen, "Three-dimensional simulation of liquid water distribution in a PEMFC with experimentally measured capillary functions," Journal of the Electrochemical Society, vol. 154, no. 12, pp. B1242-B1251, 2007.

[35] X.-D. Wang, Y.-L. Wang, Y. Chen, C. Si, A. Su, and D.-J. Lee, "Proton exchange membrane fuel cell modeling with diffusion layer-based and sands-based capillary pressure correlations: comparative study," Journal of the Taiwan Institute of Chemical Engineers, vol. 45, no. 4, pp. 1532-1541, 2014.

[36] E. C. Kumbur, K. V. Sharp, and M. M. Mench, "A design tool for predicting the capillary transport characteristics of fuel cell diffusion media using an artificial neural network," Journal of Power Sources, vol. 176, no. 1, pp. 191-199, 2008.

[37] E. C. Kumbur, K. V. Sharp, and M. M. Mench, "Validated leverett approach for multiphase flow in PEFC diffusion media. I. Hydrophobicity effect," Journal of the Electrochemical Society, vol. 154, no. 12, pp. B1295-B1304, 2007.

[38] E. C. Kumbur, K. V. Sharp, and M. M. Mench, "Validated leverett approach for multiphase flow in PEFC diffusion media: II. Compression effect," Journal of the Electrochemical Society, vol. 154, no. 12, pp. B1305-B1314, 2007.

[39] E. C. Kumbur, K. V. Sharp, and M. M. Mench, "Validated leverett approach for multiphase flow in PEFC diffusion media: 
III. Temperature effect and unified approach," Journal of the Electrochemical Society, vol. 154, no. 12, pp. B1315-B1324, 2007.

[40] J. T. Gostick, M. W. Fowler, M. A. Ioannidis, M. D. Pritzker, Y. M. Volfkovich, and A. Sakars, "Capillary pressure and hydrophilic porosity in gas diffusion layers for polymer electrolyte fuel cells," Journal of Power Sources, vol. 156, no. 2, pp. 375-387, 2006.

[41] M. Acosta, C. Merten, G. Eigenberger et al., "Modeling nonisothermal two-phase multicomponent flow in the cathode of PEM fuel cells," Journal of Power Sources, vol. 159, no. 2, pp. 11231141, 2006.

[42] J. D. Fairweather, P. Cheung, J. St-Pierre, and D. T. Schwartz, "A microfluidic approach for measuring capillary pressure in PEMFC gas diffusion layers," Electrochemistry Communications, vol. 9, no. 9, pp. 2340-2345, 2007.

[43] J. T. Gostick, M. A. Ioannidis, M. W. Fowler, and M. D. Pritzker, "Direct measurement of the capillary pressure characteristics of water-air-gas diffusion layer systems for PEM fuel cells," Electrochemistry Communications, vol. 10, no. 10, pp. 1520-1523, 2008.

[44] T. V. Nguyen, G. Lin, H. Ohn, and X. Wang, "Measurement of capillary pressure property of gas diffusion media used in proton exchange membrane fuel cells," Electrochemical and Solid-State Letters, vol. 11, no. 8, pp. B127-B131, 2008.

[45] T. Koido, T. Furusawa, and K. Moriyama, "An approach to modeling two-phase transport in the gas diffusion layer of a proton exchange membrane fuel cell," Journal of Power Sources, vol. 175, no. 1, pp. 127-136, 2008.

[46] K. G. Gallagher, R. M. Darling, T. W. Patterson, and M. L. Perry, "Capillary pressure saturation relations for PEM fuel cell gas diffusion layers," Journal of the Electrochemical Society, vol. 155, no. 11, pp. B1225-B1231, 2008.

[47] D. Rensink, J. Roth, and S. Fell, "Liquid water transport and distribution in fibrous porous media and gas channels," in Proceedings of the 6th International Conference on Nanochannels, Microchannels, and Minichannels (ICNMM '08), pp. 1271-1277, Darmstadt, Germany, June 2008.

[48] P. Cheung, J. D. Fairweather, and D. T. Schwartz, "Characterization of internal wetting in polymer electrolyte membrane gas diffusion layers," Journal of Power Sources, vol. 187, no. 2, pp. 487-492, 2009.

[49] I. R. Harkness, N. Hussain, L. Smith, and J. D. B. Sharman, "The use of a novel water porosimeter to predict the water handling behaviour of gas diffusion media used in polymer electrolyte fuel cells," Journal of Power Sources, vol. 193, no. 1, pp. 122-129, 2009.

[50] J. T. Gostick, M. A. Ioannidis, M. W. Fowler, and M. D. Pritzker, "On the role of the microporous layer in PEMFC operation," Electrochemistry Communications, vol. 11, no. 3, pp. 576-579, 2009.

[51] J. T. Gostick, M. A. Ioannidis, M. W. Fowler, and M. D. Pritzker, "Wettability and capillary behavior of fibrous gas diffusion media for polymer electrolyte membrane fuel cells," Journal of Power Sources, vol. 194, no. 1, pp. 433-444, 2009.

[52] J. D. Fairweather, P. Cheung, and D. T. Schwartz, "The effects of wetproofing on the capillary properties of proton exchange membrane fuel cell gas diffusion layers," Journal of Power Sources, vol. 195, no. 3, pp. 787-793, 2010.

[53] L. Hao and P. Cheng, "Capillary pressures in carbon paper gas diffusion layers having hydrophilic and hydrophobic pores," International Journal of Heat and Mass Transfer, vol. 55, no. 1-3, pp. 133-139, 2012.
[54] J. T. Gostick, M. A. Ioannidis, M. W. Fowler, and M. D. Pritzker, "Chapter 7: characterization of the capillary properties of gas diffusion media," in Modeling and Diagnostics of Polymer Electrolyte Fuel Cells, vol. 49 of Modern Aspects of Electrochemistry, pp. 225-254, Springer, New York, NY, USA, 2010.

[55] J. T. Gostick, H. Gunterman, B. Kienitz, J. Newman, A. MacDowell, and A. Weber, "Tomographic imaging of water injection and withdrawal in PEMFC gas diffusion layers," ECS Transactions, vol. 33, no. 1, pp. 1407-1412, 2010.

[56] J. T. Gostick, M. A. Ioannidis, M. D. Pritzker, and M. W. Fowler, "Impact of liquid water on reactant mass transfer in PEM fuel cell electrodes," Journal of the Electrochemical Society, vol. 157, no. 4, pp. B563-B571, 2010.

[57] J. T. Gostick, "Random pore network modeling of GDLs using Voronoi and Delaunay tessellations," ECS Transactions, vol. 41, no. 1, pp. 125-130, 2011.

[58] K. P. Shrestha and J. T. Gostick, "Measurement of capillary pressure curves in GDLs at elevated temperatures," ECS Transactions, vol. 50, no. 2, pp. 469-476, 2013.

[59] T. V. Nguyen, G. Lin, H. Ohn, D. Hussey, D. Jacobson, and M. Arif, "Measurements of two-phase flow properties of the porous media used in PEM fuel cells," ECS Transactions, vol. 3, no. 1, pp. 415-423, 2006.

[60] J. D. Sole and M. W. Ellis, "Determination of the relationship between capillary pressure and saturation in PEMFC gas diffusion media," in Proceedings of the 6th International Conference on Fuel Cell Science, Engineering, and Technology, pp. 829-840, Denver, Colo, USA, June 2008.

[61] U. Pasaogullari and C. Y. Wang, "Liquid water transport in gas diffusion layer of polymer electrolyte fuel cells," Journal of the Electrochemical Society, vol. 151, no. 3, pp. A399-A406, 2004.

[62] W.-M. Yan, D.-K. Wu, X.-D. Wang, A.-L. Ong, D.-J. Lee, and A. $\mathrm{Su}$, "Optimal microporous layer for proton exchange membrane fuel cell," Journal of Power Sources, vol. 195, no. 17, pp. 5731-5734, 2010.

[63] X.-D. Wang, X.-X. Zhang, W.-M. Yan, D.-J. Lee, and A. Su, "Non-isothermal effects of single or double serpentine proton exchange membrane fuel cells," Electrochimica Acta, vol. 55, no. 17, pp. 4926-4934, 2010.

[64] C. Lim and C. Y. Wang, "Measurement of contact angles of liquid water in PEM fuel cell gas diffusion layer (GDL) by sessile drop and capillary rise methods," Penn State University Electrochemical Engine Center (ECEC) Technical Report 200103, Penn State University, State College, Pa, USA, 2001.

[65] M. Mathias, J. Roth, W. Lehnert, and J. Fleming, Handbook of Fuel Cells-Fundamentals, Technology and Applications, vol. 3, chapter 42, John Wiley \& Sons, New York, NY, USA, 2003.

[66] X. D. Wang, X. F. Peng, and B. X. Wang, "Contact angle hysteresis and hysteresis tension on rough solid surface," Chinese Journal of Chemical Engineering, vol. 12, no. 5, pp. 615-621, 2004.

[67] X. D. Wang, D. J. Lee, X. F. Peng, and J. Y. Lai, "Spreading dynamics and dynamic contact angle of non-newtonian fluids," Langmuir, vol. 12, no. 15, pp. 8042-8047, 2007.

[68] X. D. Wang, Y. Zhang, D. J. Lee, and X. F. Peng, "Spreading of completely wetting or partially wetting power-law fluid on solid surface," Langmuir, vol. 23, no. 18, pp. 9258-9262, 2007.

[69] W. L. Gao, Petrophysics, China University of Petroleum Press, Beijing, China, 2009.

[70] T. A. Trabold, J. P. Owejan, D. L. Jacobson, M. Arif, and P. R. Huffman, "In situ investigation of water transport in an operating PEM fuel cell using neutron radiography: part 
1-experimental method and serpentine flow field results," International Journal of Heat and Mass Transfer, vol. 49, no. 2526, pp. 4712-4720, 2006.

[71] R. Satija, D. L. Jacobson, M. Arif, and S. A. Werner, "In situ neutron imaging technique for evaluation of water management systems in operating PEM fuel cells," Journal of Power Sources, vol. 129, no. 2, pp. 238-245, 2004.

[72] Z. Lu, S. G. Kandlikar, C. Rath et al., "Water management studies in PEM fuel cells-part II: ex situ investigation of flow maldistribution, pressure drop and two-phase flow pattern in gas channels," International Journal of Hydrogen Energy, vol. 34, no. 8, pp. 3445-3456, 2009.

[73] J. Becker, V. Schulz, and A. Wiegmann, "Numerical determination of two-phase material parameters of a gas diffusion layer using tomography images," Journal of Fuel Cell Science and Technology, vol. 5, no. 2, Article ID 021006, 2008.

[74] V. P. Schulz, J. Becker, A. Wiegmann, P. P. Mukherjee, and C.Y. Wang, "Modeling of two-phase behavior in the gas diffusion medium of PEFCs via full morphology approach," Journal of the Electrochemical Society, vol. 154, no. 4, pp. B419-B426, 2007.

[75] N. R. Morrow and N. Mungan, "Wettability and capillary in porous media," Report RR-7, Petroleum Recovery Research Institute, Calgary, Canada, 1971.

[76] N. R. Morrow, "Capillary pressure correlations for uniformly wetted porous media," Journal of Canadian Petroleum Technology, vol. 15, no. 4, pp. 49-69, 1976.

[77] H.-K. Lee, J.-H. Park, D.-Y. Kim, and T.-H. Lee, "A study on the characteristics of the diffusion layer thickness and porosity of the PEMFC," Journal of Power Sources, vol. 131, no. 1-2, pp. $200-$ 206, 2004.

[78] C. S. Kong, D.-Y. Kim, H.-K. Lee, Y.-G. Shul, and T.-H. Lee, "Influence of pore-size distribution of diffusion layer on masstransport problems of proton exchange membrane fuel cells," Journal of Power Sources, vol. 108, no. 1-2, pp. 185-191, 2002.

[79] L. R. Jordan, A. K. Shukla, T. Behrsing, N. R. Avery, B. C. Muddle, and M. Forsyth, "Effect of diffusion-layer morphology on the performance of polymer electrolyte fuel cells operating at atmospheric pressure," Journal of Applied Electrochemistry, vol. 30, no. 6, pp. 641-646, 2000.

[80] E. Passalacqua, G. Squadrito, F. Lufrano, A. Patti, and L. Giorgi, "Effects of the diffusion layer characteristics on the performance of polymer electrolyte fuel cell electrodes," Journal of Applied Electrochemistry, vol. 31, no. 4, pp. 449-454, 2001.

[81] E. Antolini, A. Pozio, L. Giorgi, and E. Passalacqua, "Morphological characteristics of carbon/polytetrafluoroethylene films deposited on porous carbon support," Journal of Materials Science, vol. 33, no. 7, pp. 1837-1843, 1998.

[82] M. V. Williams, E. Begg, L. Bonville, H. R. Kunz, and J. M. Fenton, "Characterization of gas diffusion layers for PEMFC," Journal of the Electrochemical Society, vol. 151, no. 8, pp. A1173A1180, 2004.

[83] J. Ihonen, M. Mikkola, and G. Lindbergh, "Flooding of gas diffusion backing in PEFCs: physical and electrochemical characterization," Journal of the Electrochemical Society, vol. 151, no. 8, pp. A1152-A1161, 2004.

[84] M. Prasanna, H. Y. Ha, E. A. Cho, S. A. Hong, and I. H. Oh, "Influence of cathode gas diffusion media on the performance of the PEMFCs," Journal of Power Sources, vol. 131, no. 1-2, pp. 147-154, 2004.

[85] J. T. Gostick, Multiphase mass transfer and capillary properties of gas diffusion layers for polymer electrolyte membrane fuel cells [Ph.D. thesis], The University of Waterloo, 2008.
[86] J. Sole, Investigation of water transport parameters and processes in the gas diffusion layer of PEM fuel cells [Ph.D. thesis], Virginia Poly Technical Institute, Blacksburg, Va, USA, 2008.

[87] J. Divisek, R. Wilkenhöner, and Y. Volfkovich, "Structure investigations of SOFC anode cermets. Part I. Porosity investigations," Journal of Applied Electrochemistry, vol. 29, no. 2, pp. 153-163, 1999.

[88] J. Divisek, M. Eikerling, V. Mazin, H. Schmitz, U. Stimming, and Y. M. Volfkovich, "A study of capillary porous structure and sorption properties of nafion proton-exchange membranes swollen in water," Journal of the Electrochemical Society, vol. 145, no. 8, pp. 2677-2683, 1998.

[89] J. H. Nam and M. Kaviany, "Effective diffusivity and watersaturation distribution in single- and two-layer PEMFC diffusion medium," International Journal of Heat and Mass Transfer, vol. 46, no. 24, pp. 4595-4611, 2003.

[90] G. Y. Lin and T. V. Van Nguyen, "A two-dimensional two-phase model of a PEM fuel cell," Journal of the Electrochemical Society, vol. 153, no. 2, pp. A372-A382, 2006.

[91] D. Natarajan and T. Van Nguyen, "A two-dimensional, twophase, multicomponent, transient model for the cathode of a proton exchange membrane fuel cell using conventional gas distributors," Journal of the Electrochemical Society, vol. 148, no. 12, pp. a1324-a1335, 2001.

[92] X. D. Wang and C. Si, "The efforts of gas diffusion layer properties on the performance of proton exchange membrane fuel cell: a following study based on experimental measurements of gas diffusion layers," Tech. Rep. 2014-02, Department of Renewable Energy of North China Electric Power University, Beijing, China, 2014. 

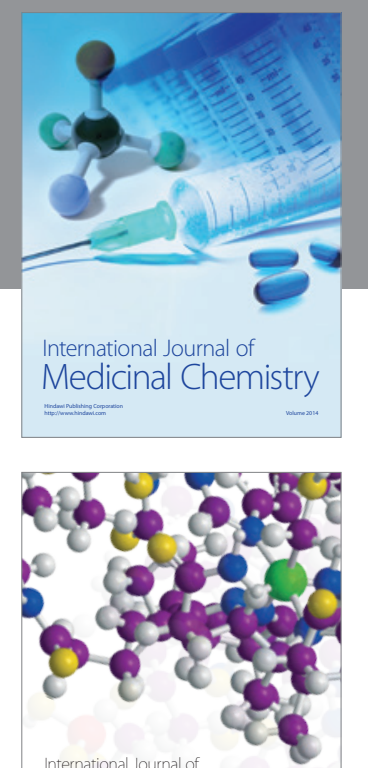

\section{Carbohydrate} Chemistry

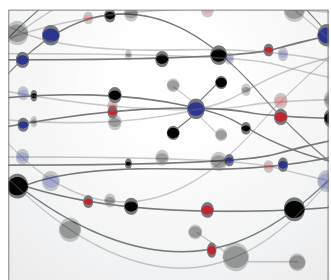

The Scientific World Journal
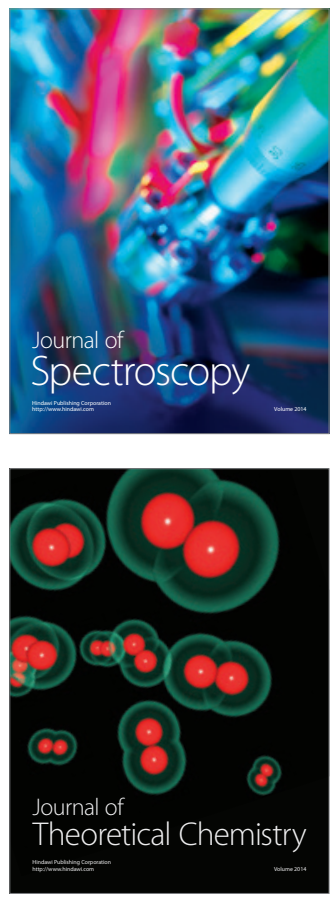
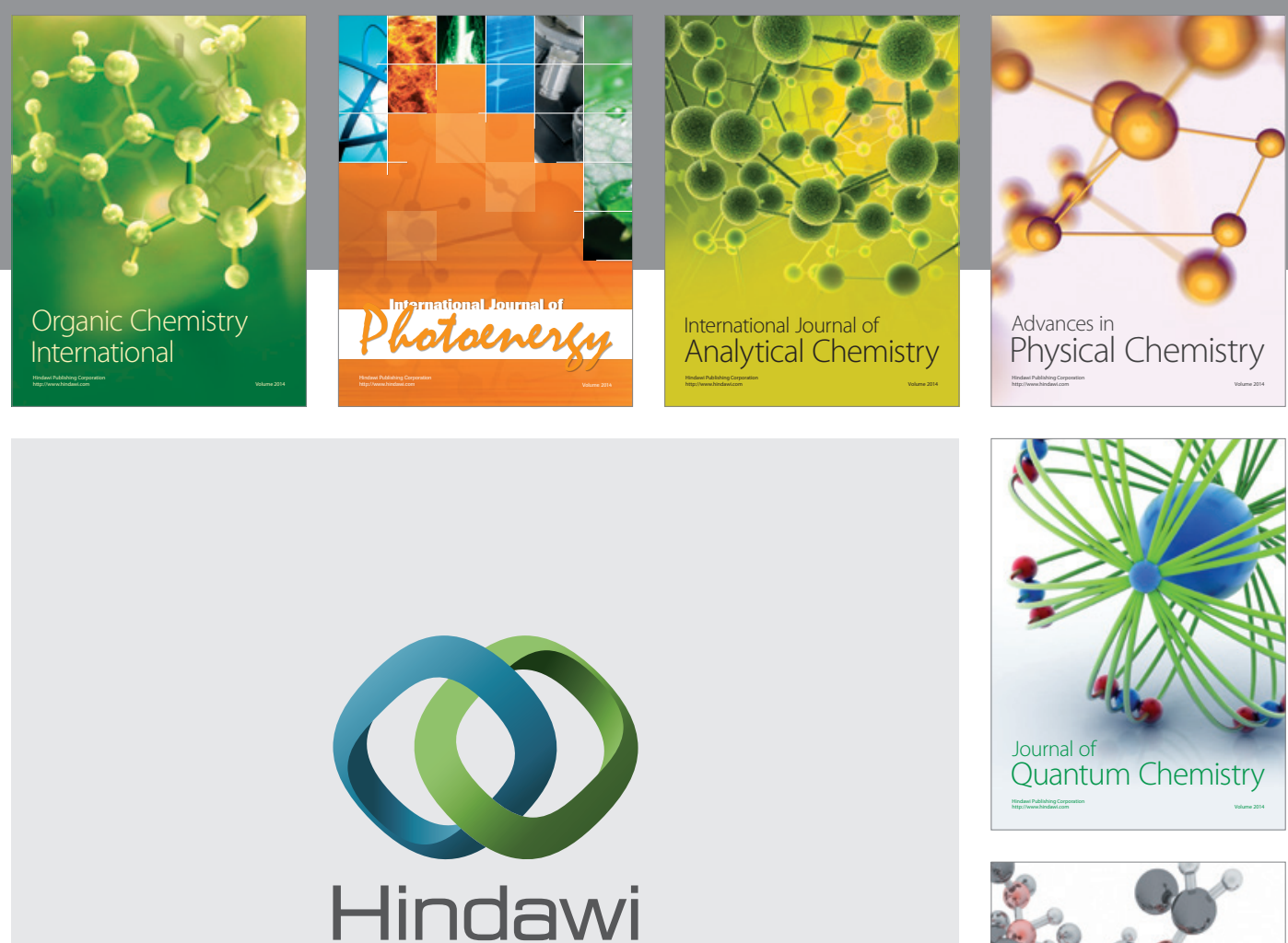

Submit your manuscripts at

http://www.hindawi.com

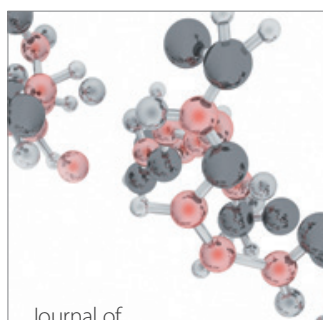

Analytical Methods

in Chemistry

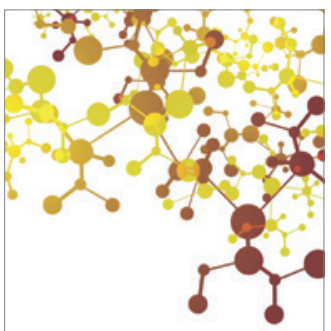

Journal of

Applied Chemistry

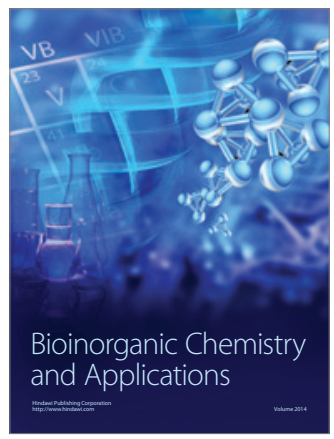

Inorganic Chemistry
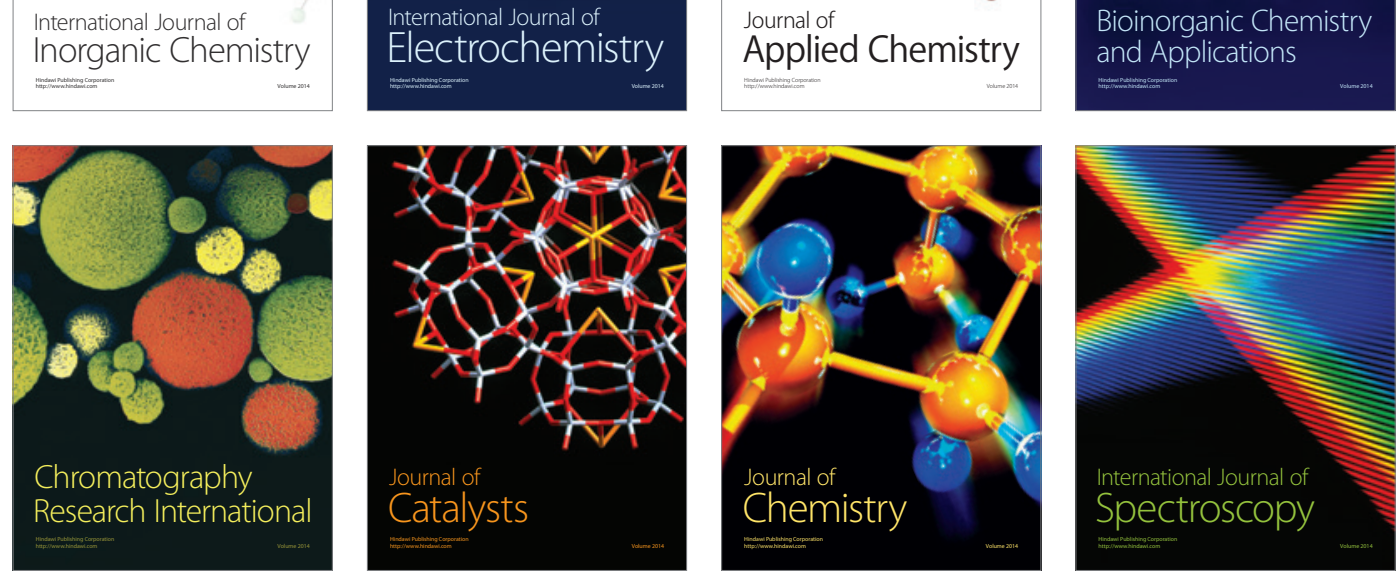